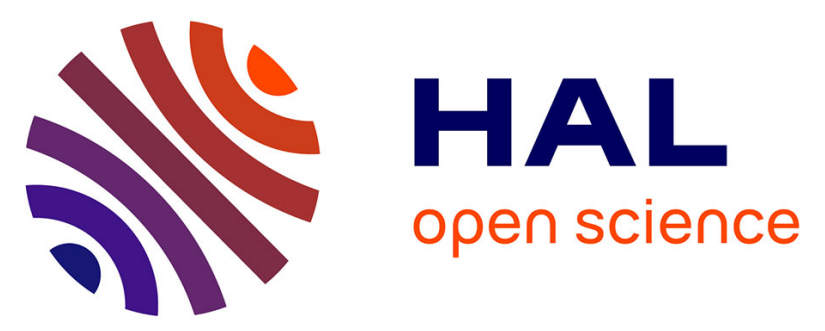

\title{
Mechanical Response of Shallow Crust to Groundwater Storage Variations: Inferences from Deformation and Seismic Observations in the Eastern Southern Alps, Italy
}

F. Pintori, E. Serpelloni, Laurent Longuevergne, A. Garcia, L. Faenza, L. D'alberto, A. Gualandi, M. Belardinelli

\section{To cite this version:}

F. Pintori, E. Serpelloni, Laurent Longuevergne, A. Garcia, L. Faenza, et al.. Mechanical Response of Shallow Crust to Groundwater Storage Variations: Inferences from Deformation and Seismic Observations in the Eastern Southern Alps, Italy. Journal of Geophysical Research: Solid Earth, 2021, 126 (2), pp.e2020JB020586. 10.1029/2020JB020586 . insu-03121807

\section{HAL Id: insu-03121807 https://hal-insu.archives-ouvertes.fr/insu-03121807}

Submitted on 16 Aug 2021

HAL is a multi-disciplinary open access archive for the deposit and dissemination of scientific research documents, whether they are published or not. The documents may come from teaching and research institutions in France or abroad, or from public or private research centers.
L'archive ouverte pluridisciplinaire HAL, est destinée au dépôt et à la diffusion de documents scientifiques de niveau recherche, publiés ou non, émanant des établissements d'enseignement et de recherche français ou étrangers, des laboratoires publics ou privés. 


\section{JGR Solid Earth}

\author{
RESEARCH ARTICLE \\ 10.1029/2020JB020586 \\ Key Points: \\ - Regional groundwater storage \\ changes in heterogeneous media \\ modulate horizontal transient \\ deformation \\ - Water pressure changes in shallow \\ permeable fractures cause large \\ elastic stress changes at seismogenic \\ depth \\ - Background seismicity rates are \\ correlated with groundwater storage \\ changes
}

Supporting Information:

- Supporting Information S1

- Movie S1

Correspondence to:

F. Pintori,

francesco.pintori@ingv.it

Citation:

Pintori, F., Serpelloni, E.,

Longuevergne, L., Garcia, A.,

Faenza, L., D'Alberto, L., et al. (2021).

Mechanical response of shallow crust

to groundwater storage variations:

Inferences from deformation and

seismic observations in the eastern

Southern Alps, Italy. Journal of

Geophysical Research: Solid Earth,

126, e2020JB020586. https://doi.

org/10.1029/2020JB020586

Received 13 JUL 2020

Accepted 20 JAN 2021

(C) 2021. American Geophysical Union. All Rights Reserved.

\section{Mechanical Response of Shallow Crust to Groundwater Storage Variations: Inferences From Deformation and Seismic Observations in the Eastern Southern Alps, Italy}

\author{
Francesco Pintori $i^{1,2}$ (1) Enrico Serpelloni $^{1}$ (D), Laurent Longuevergne ${ }^{3}$ (i),

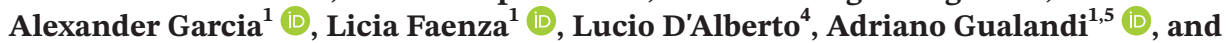 \\ Maria Elina Belardinelli ${ }^{2}$ (D)
}

${ }^{1}$ Istituto Nazionale di Geofisica e Vulcanologia, Bologna, Italy, ${ }^{2}$ Dipartimento di Fisica e Astronomia, Settore di Geofisica, Università di Bologna, Bologna, Italy, ${ }^{3}$ Univ Rennes, CNRS, Geosciences Rennes, Rennes, France, ${ }^{4}$ ARPA Veneto, Inland Waters Office, Padova, Italy, ${ }^{5}$ Department of Geological and Planetary Sciences, California Institute of Technology, Pasadena, CA, USA

\begin{abstract}
Changes in continental water storage generate vertical surface deformation, induce crustal stress perturbations, and modulate seismicity rates. However, the degree to which regional changes in terrestrial water content influence crustal stresses and the occurrence of earthquakes remains an open problem. We show how changes in groundwater storage, computed for a $\sim 1,000 \mathrm{~km}^{2}$ basin, focus deformation in a narrow zone, causing large horizontal, nonseasonal displacements. We present results from a karstic mountain range located at the edge of the Adria-Eurasia plate boundary system in Northern Italy, where shortening is accommodated across an active fold-and-thrust belt. The presence of geological structures with high permeabilities and of deeply rooted hydrologically active fractures focus groundwater fluxes and pressure changes, generating transient surface horizontal displacements up to $5 \mathrm{~mm}$ and perturbations of crustal stress up to $25 \mathrm{kPa}$ at seismogenic depths. The background seismicity rates appear correlated, without evident temporal delay, with groundwater storage changes in the hydrological basin. With no evidence of pore pressure propagation from the hydrologically active fractures, seismicity modulation is likely affected by direct stress changes on faults planes.
\end{abstract}

Plain Language Summary The natural water cycle, by changing how water is stored on the continents, can cause nonnegligible deformation at the Earth's surface. Redistribution of water masses has long been known to alter the state of stress in the crust and potentially modulate seismicity rates. However, the degree to which regional changes in groundwater storage influence crustal stresses and the occurrence of earthquakes at fault scales remains an open problem. We study a karst area located in a tectonically active region of Northern Italy, where plate convergence is accommodated across a complex system of faults and folds. We use GPS, hydrological, meteorological and seismological observations, integrated by hydrological and mechanical models, to show that there is a direct elastic connection between changes in groundwater storage, crustal deformation, and seismicity rates. We show that hydrologically active fractures and seismically active fractures might be disjoint, and that pore pressure propagation is not required to generate stress changes at seismogenic depths. Indeed, the convergence of water from upstream catchment toward permeable fractures connected to the surface can generate large pressure changes on the wall of these fractures, causing horizontal displacements and perturbations of the crustal stress that modulate background seismicity rates.

\section{Introduction}

Constant redistribution of surface loads due to continental hydrology (van Dam et al., 2001) causes measurable deformation of the Earth's surface. In particular, seasonal hydrological mass movements turned out to influence tectonic deformation of the lithosphere and modulate seismicity rates in several tectonic environments (e.g., Bettinelli et al., 2008; Craig et al., 2017; Johnson et al., 2020; Lowry, 2006). While seasonal modulation of seismicity associated with vertical loading is a known process, hydrologically driven deformation mainly acting on the horizontal components have been more recently recognized. Silverii et al. (2020) describe horizontal seasonal deformation caused by poroelastic processes related to snow- 
melt runoff water infiltrating into the Sierra Nevada slopes around Long Valley Caldera (USA); Oestreicher (2018) shows repetitive and reversible horizontal movements of up to $\sim 55 \mathrm{~mm}$ on annual scales, strongly correlated with modeled groundwater levels in Southern Alps (New Zealand); Silverii et al. (2016) recognize transient deformation signals in GPS horizontal time series, controlled by seasonal and interannual phases of groundwater recharge/discharge of karst aquifers in the Apennines (Italy); Devoti et al (2015) and Serpelloni et al. (2018) describe horizontal transient deformation signals in the Southern Alps (Italy), correlated with precipitation.

Both in the Apennines and in the Alps, changes in groundwater levels in karst aquifers, or fractures associated with karst systems, are considered the most likely mechanisms to explain the observed deformation, which is characterized by larger displacements in the horizontal components than in the vertical one. Since direct measurements of groundwater levels at regional scale (1-10.000 $\left.\mathrm{km}^{2}\right)$ are difficult to obtain, particularly in mountain regions, such as in the study area (see Figure 8 from Chen et al., 2018), the hydrological nature of these aforementioned deformation signals has been suggested based on temporal correlation between geodetic displacements and meteorological and hydrological data like precipitation, spring discharge, river flow, snow water equivalent and lake levels. The Gravity Recovery and Climate Experiment (GRACE) provides complementary independent observations of terrestrial water storage changes (TWS), but its spatial resolution is lower than scales of $300 \mathrm{~km}$ (Famiglietti et al., 2011). As a result, at spatial scales significantly lower than the GRACE resolution, when direct measurements of groundwater storage changes (GWS) are not available (e.g., because of the lack of water wells) the geodetic signals are more often correlated with groundwater data (mainly precipitation and spring discharge). Serpelloni et al. (2018) studying the Adria-Eurasia plate boundary in Italy and Slovenia showed that detected geodetic transient signals are poorly correlated with daily precipitation data, but highly correlated, without temporal delay, with the history of cumulated precipitations at monthly time scales. However, the physical interpretation of this monthly scale cumulative precipitation signal, in terms of hydrological cycle and GWS, is not straightforward.

Identifying and extracting nontectonic signals from geodetic measurements remains critical to detect potential tectonic signals of small amplitude and to improve the accuracy and precision of interseismic deformation estimates. Moreover, studying hydrological deformation signals can provide new clues on elastic (Chanard et al., 2014; Drouin et al., 2016) and viscoelastic (Chanard et al., 2018) properties of the Earth, on water storage fluctuations (Borsa et al., 2014; Fu et al., 2013) and on the possible relationship between hydrologically driven stress changes and earthquake nucleation. Two mechanisms by which the natural water cycle can modulate earthquake occurrence have been suggested: variations in pore-fluid pressure at hypocentral depths (Hainzl et al., 2006) and direct stress on the fault plane (Bettinelli et al., 2008; Craig et al., 2017; D'Agostino et al., 2018; Johnson et al., 2017). An effective way to discriminate between these two processes is the presence of a time lag between hydrological indicators and seismicity rates. In fact, while the effect of the direct stress can be considered instantaneous, pore-pressure propagation exhibits a time lag between hydrological and seismological indicators, if pore-fluid pressure variations are the main driver of earthquake rates modulation. The time lag $\tau$ is linked to both flow distance $L$ and media/fracture diffusivity $D$ by $\tau=L^{2} / D$ (Schuite et al., 2017).

In this work we study a segment of the Adria-Eurasia plate boundary in North-Eastern Italy (Figure 1), hit by strong historical earthquakes (e.g., the $M w$ 6.5, 1695 Asolo earthquake; Rovida et al., 2020) and where the larger part of plate convergence is presently accommodated across a south-verging fold-and-thrust belt (Anderlini et al., 2020; Serpelloni et al., 2016). The main thrusts are, from the internal parts to the foreland, the Valsugana thrust, the Belluno thrust, and the Bassano-Valdobbiadene thrust (BVT), the latter being associated with a morphological relief of $\sim 1,200 \mathrm{~m}$ above the plain, known as Pedemountain flexure (Figure 1). The southernmost active front is now mainly buried beneath the alluvial deposits of the Venetian plain and sealed by Late Miocene to Quaternary ( 7-2.5 Ma) deposits (Fantoni et al., 2002), consisting in the Montello thrust (Fantoni et al., 2002; Galadini et al., 2005). The Montello hill (Figure 1) is generally interpreted as an actively growing ramp anticline on top of the north dipping thrust that has migrated south of the mountain into the foreland (Serpelloni et al., 2016).

The main geomorphological feature of the area is the presence of the NE-SW oriented Belluno Valley, where the Piave river flows, bounded to the north by the Dolomites and to the south by the Monte Grappa massif, 

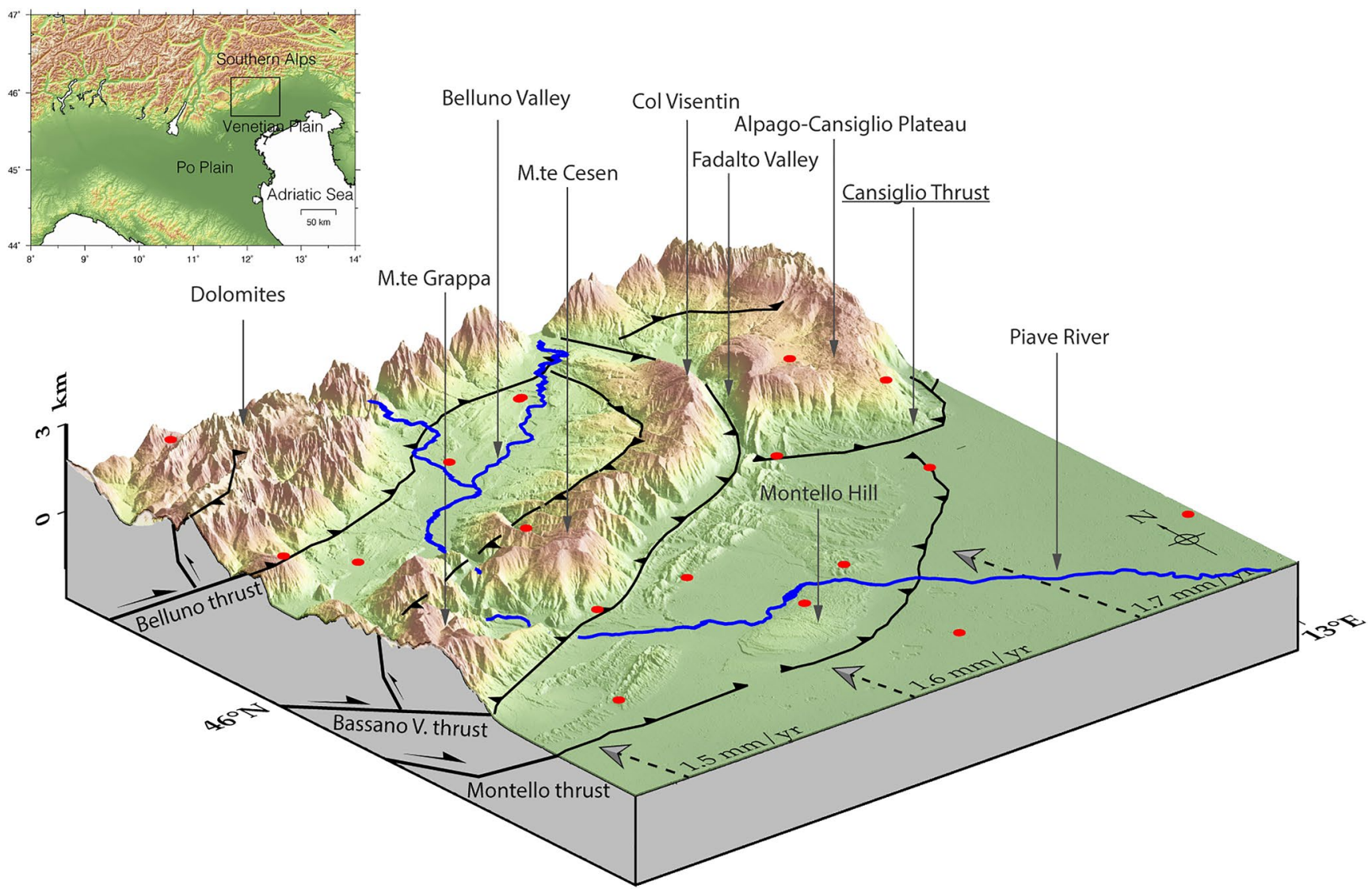

Figure 1. 3D view (from SW) of the study area. The dashed arrows indicate the Adria-Eurasia convergence rate and direction, predicted from a GNSS-derived rotation pole (Serpelloni et al., 2016). The digital elevation model, with topographic exaggeration, is obtained from ALOS Global Digital Surface Model data. The black lines represent the major fault lines (fault names are reported in the vertical section or with underlined text). The red dots indicate the position of the GPS stations.

the Monte Cesen-Col Visentin (MCCV) mountain chain and the Alpago-Cansiglio plateau (see Figure 1). The MCCV is the morphological expression of an anticline associated with the BVT and back thrust system, and it is crossed by the Piave river that flows to the southeast reaching the Montello hill. Three highly productive fissured, hydrologically independent, karst aquifers are present in the area (Figure 3; Filippini et al., 2018): the Dolomites, one associated with the MCCV and one with the Alpago-Cansiglio plateau.

In this work, we link the natural water cycle to crustal deformation and geological structures by adopting physically based approach, depending on a hydrological and mechanical model constrained by precipitation, temperature and river flow data and subsurface geological information. The model explains both amplitude and spatial patterns of the horizontal deformation observed on GNSS sites. We show how water collected in a $\sim 1,000 \mathrm{~km}^{2}$ basin focuses groundwater pressure changes in a relatively narrow geological structure, generating transient horizontal deformation and perturbations of crustal stress at seismogenic depths. Finally, we study the correlation between GWS and seismicity rates through a statistical approach.

\section{GNSS Data and Time-Series Analysis}

In this work, we extended the analysis carried out by Serpelloni et al. (2018), including more stations and a longer time-span, focusing on one specific sector (Figure 1) where 64 GNSS sites are present. The displacement time-series from GNSS stations in the 2010.0-2019.3 time span (Figure 2 and Figure S1), obtained following the procedures described in the Text $\mathrm{S} 1$, have been analyzed with a blind source separation algorithm based on variational Bayesian Independent Component Analysis (vbICA; Gualandi et al., 2016). This method has been successfully used to extract hydrological and tectonic transient signals from GNSS 


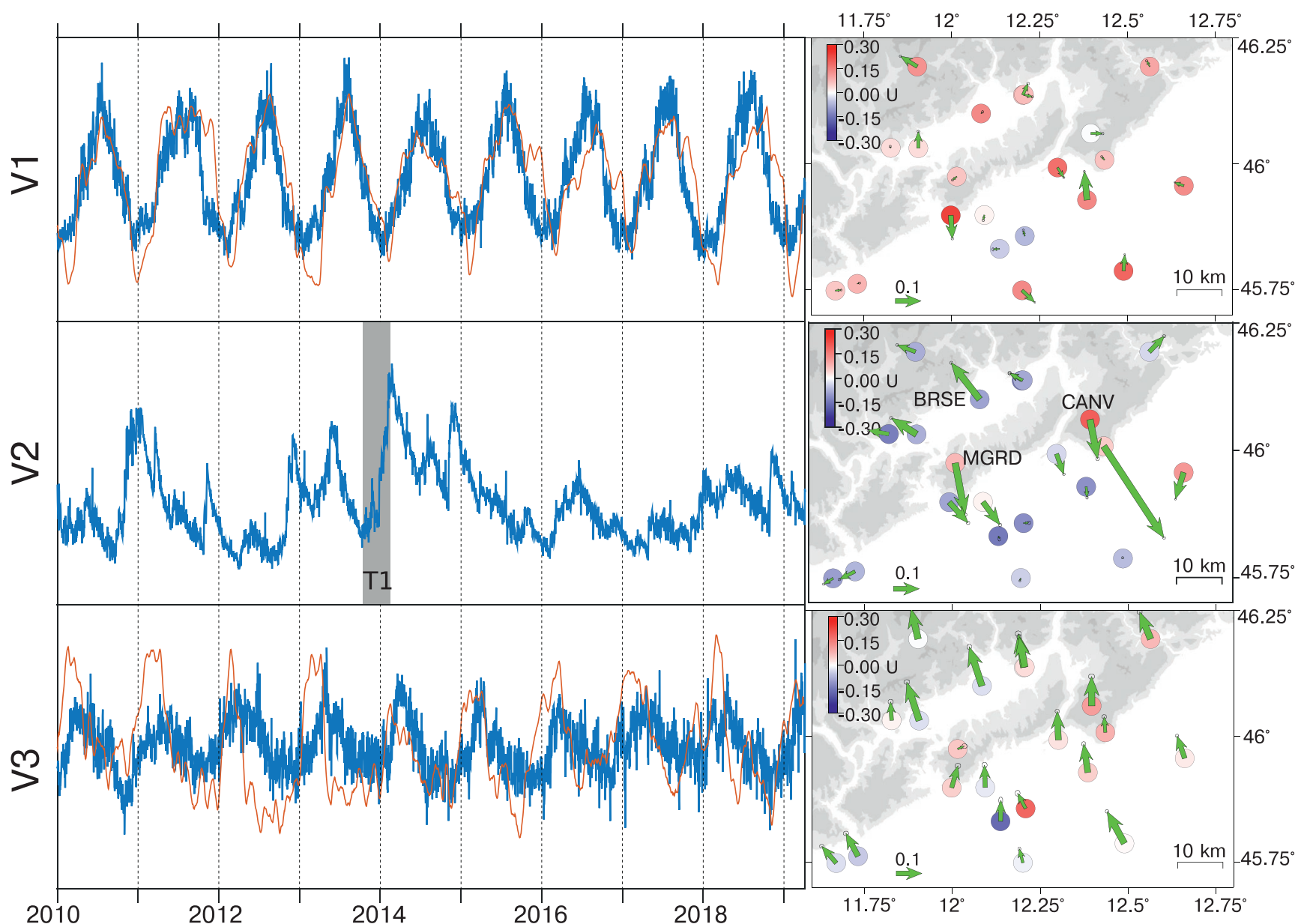

Figure 2. Temporal evolution (V; in blue) of the three ICs defined from the vbICA analysis and the corresponding spatial response in the horizontal (green arrows) and vertical (colored circles) components, respectively. The gray area indicates the time interval (T1 = October 10, 2013 to February 22, 2014) for which ground displacements have been computed and shown in Figure 3. The red lines superimposed to V1 and V3 represent the mean vertical and N-S displacements caused by surface mass loading, respectively, estimated from the ERA-interim (European Centre for Medium-Range Weather Forecasts, ECMWF reanalysis) model and provided by http://loading.u-strasbg.fr (Gegout et al., 2010). Displacements are averaged over a rectangular area with limits: lon 10.75-13.50; lat 45.25-47.00.

displacements time series (Gualandi, Nichele, et al., 2017; Gualandi, Perfettini, et al., 2017); it uses a generative model to recreate the observations and allows extracting the spatiotemporal information of independent sources of deformation directly from the observations, without imposing any specific spatial distribution or temporal function.

The output of this analysis is the definition of a limited number of sources, or components, characterized by a specific spatial distribution (U) and following a specific temporal evolution (V). A weight coefficient $\mathrm{S}$ (in $\mathrm{mm}$ ) is necessary to rescale their contribution in explaining the original data. Each independent component (IC) is described by a mix of Gaussians, which allows for more flexibility in the description of the sources with respect to classical independent component analysis (ICA) techniques; allowing to consistently take into account data gaps in the data set (Chan et al., 2003) and providing an estimate of the uncertainty associated with each IC. The displacement time series at a given station can be reconstructed by linearly summing up the contributions from all the ICs, each of which is obtained by multiplying the specific spatial distribution by the associated weight times the temporal evolution.

With the goal of reducing the correlation of the data set, the original time series are initially detrended, which results in a more efficient search of the IC direction (Gualandi et al., 2016). Differently from 


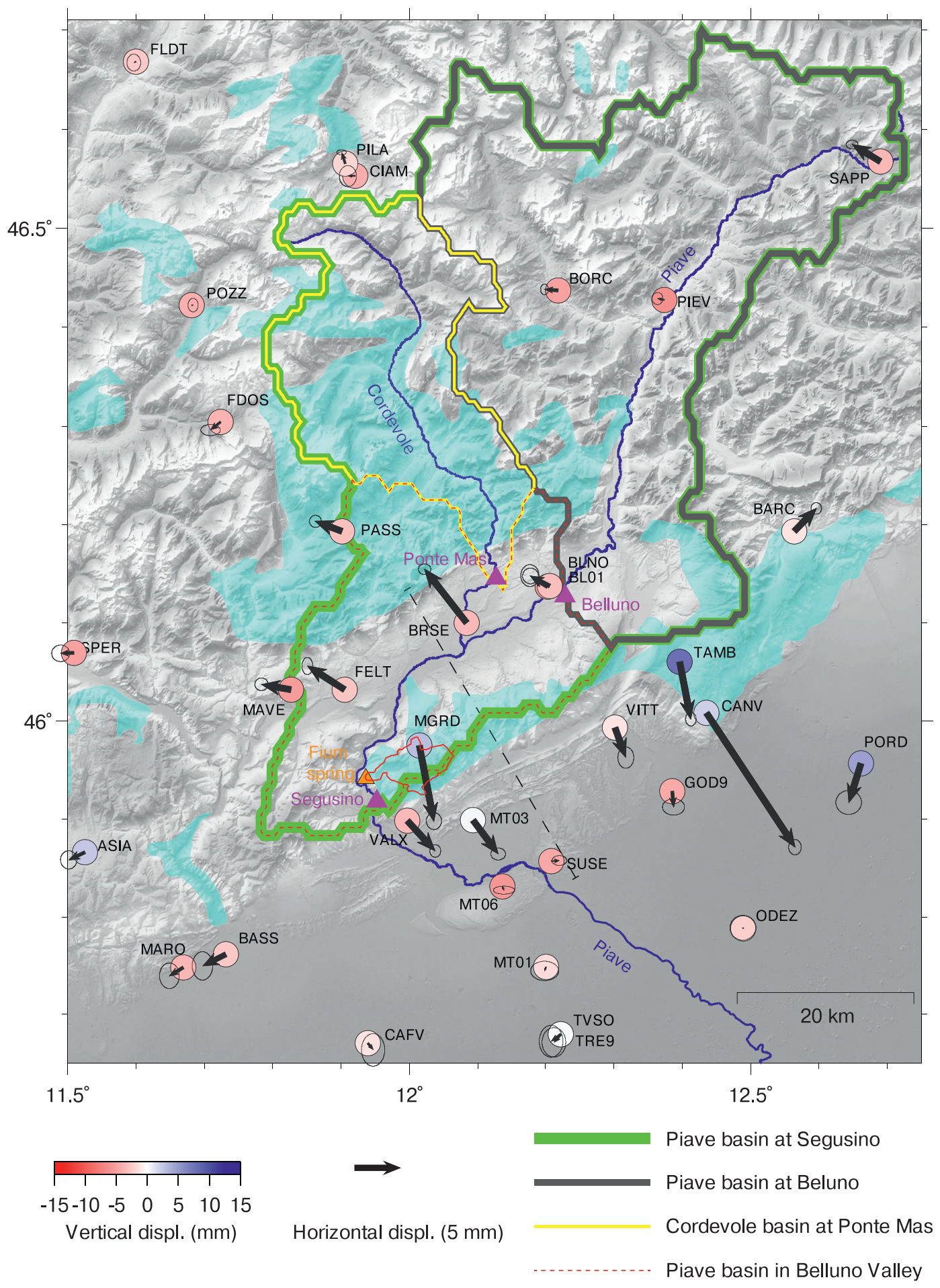

Figure 3. Hydrological map and geodetic displacements in the study region. Piave and Cordevole rivers (in blue) are gauged at three locations (purple triangles), defining three watersheds (yellow, green, and gray) and the $883 \mathrm{~km}^{2}$ region in-between (Belluno Valley, red dashed line) where water storage changes are modeled. Highly productive fissured karst aquifers are highlighted in cyan from the International Hydrogeological Map of Europe 1:1,500,000 (http://www. bgr.bund.de/ihme1500). Regional horizontal (black arrows) and vertical displacements (color dots), described by the second source of independent component analysis (IC2) on 67 GNSS stations during T1 period (winter 2013-2014), are superimposed (see also Figure 2). The dashed black line shows the trace of the geological cross section of Figure 5. 
Serpelloni et al. (2018), the trend of each GPS station is estimated in a multivariate statistical manner, by applying a vbICA analysis on displacement-time series realized in a Adria-fixed reference frame, as described in the Text S1.2. This approach is effective in removing the linear trend in case of strong nonlinear signals and short time-series.

Once detrended, we select the number of ICs to retain by applying an F-test, which establishes if the complexity introduced by an additional IC is statistically justified by the available data (e.g., Kositsky \& Avouac, 2010). We find that three ICs are necessary to satisfactorily reconstruct the observed displacements, and the improvement in the data reconstruction brought by the addition of a fourth IC is not statistically significant at $95 \%$ confidence.

The temporal evolution (V) and spatial responses (U) of the three ICs are shown in Figure 2. Seasonal annual displacements in the vertical and NS directions (IC1 and IC3) occur in response to surface hydrological mass loading (Serpelloni et al., 2018). A nonseasonal, horizontal transient deformation signal (IC2, Figure 2), characterized by spatially variable amplitudes and directions, causes GNSS stations to reverse the sense of movement with time, resulting in a sequence of dilatational and compressional deformation oriented about normal to the mountain front.

Serpelloni et al. (2018) found that the temporal evolution of this signal somehow correlates with the history of cumulated precipitations at monthly timescales. Nonetheless, the link between surface deformation and GWS remains difficult to define, because of the lack of water wells in the mountainous areas and because of the limited spatial extent of the area affected by this transient geodetic deformation signal. In the next section, we use a conceptual hydrological model to estimate daily changes in water storage to be compared with the temporal evolution of IC2, studying the link between GWS, geological structures and local seismicity rates.

\section{Hydrological Modeling of Water Storage Changes in the Piave Basin}

Water redistribution on the continents implies several processes that cover a wide range of spatial and temporal scales. At scales larger than several hundreds of kilometers, GRACE satellite observations or land surface models, such as the Global Land Data Assimilation System (GLDAS) modeling platform (Rodell, 2016), can provide a fair estimate of TWS changes and are typically used to compute surface displacements (e.g., Craig et al., 2017). At local scale, ground-based observations such as soil moisture and groundwater head can describe storage and pore-pressure changes, but their spatial representativity is limited. At regional scale, water storage observations are rare. River discharge, for example, is representative over the drained area (i.e., catchment), but only represents one flux contributing to storage changes. In this work, we model regional scale water storage changes using a rainfall-runoff model that is driven by meteorological and river discharge observations.

At catchment scale, the mass balance equation links TWS, P, E, and Q, where P, E, and Q are respectively precipitation, actual evapotranspiration, and river discharge. A subcatchment that is located between two river discharge stations (see Figure S3) can be studied as well. Here TWS can be estimated based on the mass balance equation:

$$
d T W S / d t=P+Q_{\mathrm{in}}-E-Q_{\mathrm{out}}-Q_{\mathrm{gw}}
$$

where $Q_{\text {in }}, Q_{\text {out }}$, and $Q_{\mathrm{gw}}$ are respectively incoming river inflow, outcoming river discharge, and potential groundwater import/export in a surrounding basin. Among the different water fluxes, $P, Q_{\text {in }}$, and $Q_{\text {out }}$ can be measured, whereas actual evapotranspiration and $Q_{\mathrm{gw}}$ should be estimated with a model. It is worth noting that at regional scales $(<100 \mathrm{~km})$, lateral water fluxes $\left(Q_{\mathrm{in}}, Q_{\mathrm{out}}, Q_{\mathrm{gw}}\right)$ could be significant, especially in a mountainous region, where the convergence of water from steep basins to valleys with gentle slopes favors transient accumulation of a large amount of water. Such regional-scale lateral flow processes are hardly modeled within large-scale hydrological models.

$E$ and $Q_{\mathrm{gw}}$ (Equation 1) are estimated with the lumped parameter rainfall-runoff hydrological model GR5J (Pushpalatha et al., 2011), which allow us to quantify daily TWS at the scale of each hydrological subbasins (Figure 3). This model is forced with precipitation, temperature, and potential evapotranspiration and computes actual river discharge. 
The model is based on two storage compartments-production and routing stores-which mimic the typical response of soils and groundwater to antecedent precipitation and evapotranspiration. Snow needs to be considered, especially in upstream catchments. It is estimated following the method described in the Hydrologiska Byrns Vattenbalansavdelning model (Lindstrom et al., 1997): mean catchment temperature defines both rainfall/snowfall partitioning and snow melt events.

It is worth noting that GR5J does not require a-priori information on the basin, besides mean daily values of temperature, precipitation, and potential evapotranspiration. The model is parsimonious and designed to model river discharge. However, the model does not allow us to directly estimate GWS, since it is not possible to distinguish the soil and the groundwater contribution. It is worth considering that the karstic features of the area favors water storage as groundwater instead of soil moisture or surface water. As a consequence, without groundwater level data to better constrain the model, GWS is computed as the sum of production and routing storage changes.

Although the GR5J is a simplified conceptual model, where only five mathematical parameters define the dynamics of the two stores and their relations, it has proven skillful in predicting river discharge better than more complex models (de Lavenne et al., 2016) and has been successfully applied to represent groundwater storage changes in Nepal rivers (Andermann et al., 2012). The model's parsimony is considered here as a strength given the limited information available to define actual flow and storage processes in the karst area investigated. One important feature of GR5J is the possibility to describe subsurface water exchanges with surrounding basins, as expected in karst regions.

GR5J parameters are calibrated using a Marquard-Levenberg least squares regression analysis using root mean square error on the logarithm of observed river discharge to limit the impact of floods and promote the description of the whole water cycle.

We estimate the precipitation and temperature value from January 1, 2010 to March 31, 2019 by computing a daily weighted mean of in situ measurements provided by the Veneto Regional Agency for Environmental Prevention and Protection (ARPAV, http://www.arpa.veneto.it/bollettini/storico), using the Thiessen polygon method (i.e., Natural Neighbor interpolation method, see Text S2.1). Potential evapotranspiration has been evaluated by using the Jensen-Haise method (Jensen et al., 1990; Text S2.2).

In the study area, we define three hydrological basins by using the drainage direction maps (available on www.hydrosheds.org/page/availability) and watershed outlets located at the river discharge measurements on the Piave river at Belluno, Segusino, and of the Cordevole river at Ponte Mas (see Figure 3). As the region of interest is limited to a portion of a watershed located in the Belluno Valley, between two upstream river discharge stations (Piave at Belluno, Cordevole at Ponte Mas) and the downstream station (Piave at Segusino), GR5J model is first calibrated on each catchment (see Text S2.3 for details on the modeling of each basin). Groundwater storage changes $\left(\mathrm{GWS}_{\text {res }}\right)$ in the Belluno Valley are computed as the difference between storage changes within the Piave at Segusino catchment, minus storage changes within the upstream catchments as

$$
\mathrm{GWS}_{\mathrm{res}}=\mathrm{GWS}_{\mathrm{seg}}-\left(\mathrm{GWS}_{\mathrm{cor}}+\mathrm{GWS}_{\mathrm{bel}}\right)
$$

where GWS seg $_{\text {GWS }}$, GWS bel $_{\text {cor }}$ indicate the GWS computed in the Piave at Segusino, Cordevole at Ponte Mas, and Piave at Belluno watersheds, respectively.

Figure 4 shows that the normalized temporal evolution of the second IC (V2) and GWS res are clearly correlated (Pearson correlation coefficient $=0.83$ ), demonstrating that this transient deformation component is driven by GWS. A cross-correlation analysis indicates that the correlation slightly increases (0.84) considering a time shift of 2 days, with GWS $_{\text {res }}$ anticipating V2, and falls quickly $(<0.80)$ when the time shift exceeds 15 days. The agreement is good for both short-term (rapid) $\mathrm{GWS}_{\text {res }}$ increase linked to strong precipitation events and longer-term (slower) $\mathrm{GWS}_{\text {res }}$ decrease. This process is also displayed in Movie S1.

Figure 4 also shows TWS from GRACE and GRACE-FO measurements-computed as Equivalent Water Thickness $($ EWT) - (the linear trend $=1.1 \pm 0.8 \mathrm{~cm} / \mathrm{yr}$ has been removed), processed at JPL using the Mascon approach (Version2/RL06, Watkins et al., 2015). As expected, GRACE is overall less accurate in describing water storage changes at the scale of the hydrological catchment studied in this work. EWT from 


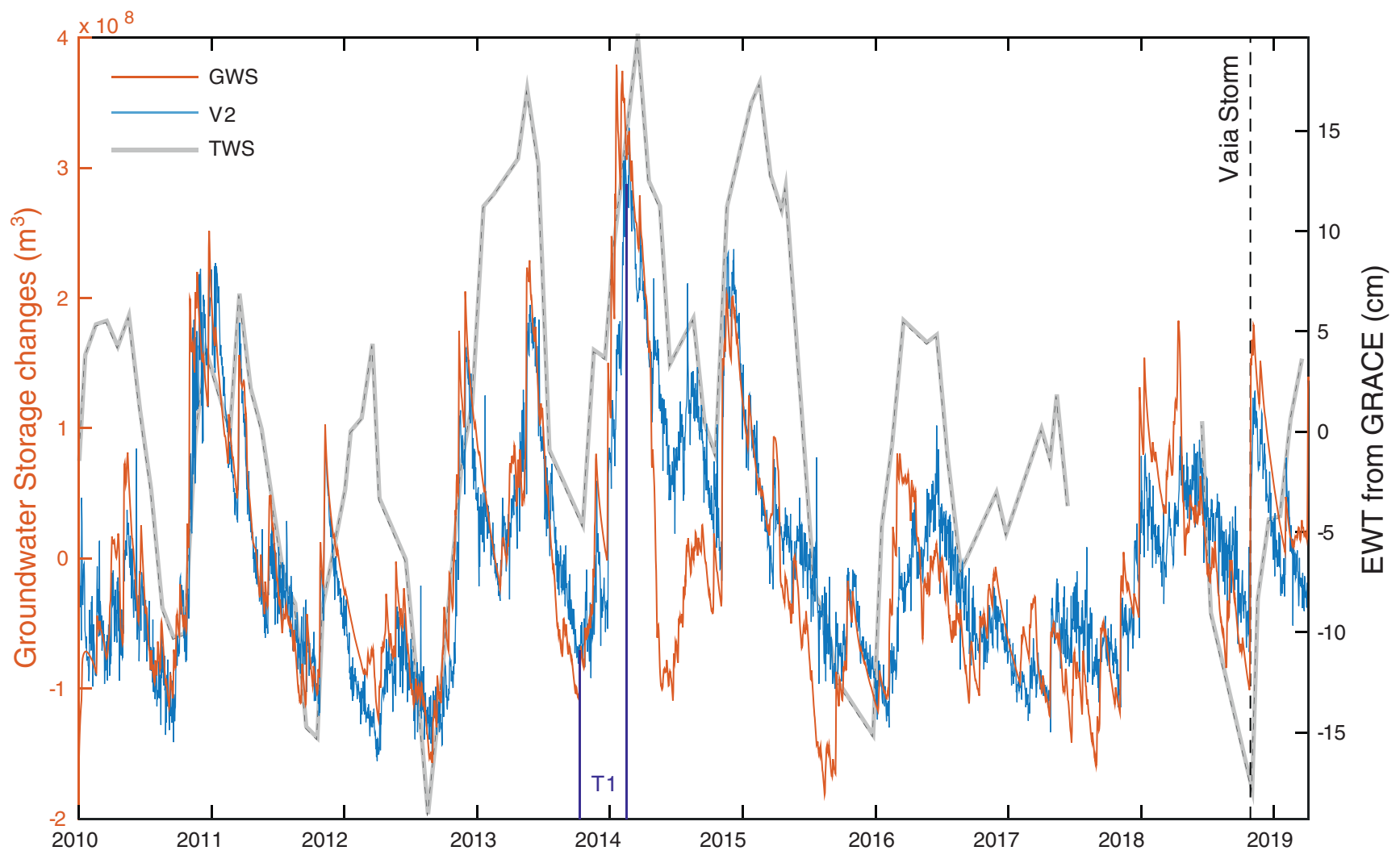

Figure 4. Temporal evolution of the modeled groundwater storage changes in the Belluno Valley (orange, left axis), the geodetic IC2 (blue) and TWS computed as EWT from GRACE and GRACE-FO measurements (gray). The linear trend of each curve has been removed (see Section 3). The blue vertical lines indicate the T1 period and the vertical dashed line shows the epoch of the intense Vaia storm.

GRACE misses most of the higher frequencies changes, resulting in a prevalent annual signal. Most importantly, it appears to be overall less accurate in representing the fast dynamics of the $1,000 \mathrm{~km}^{2}$ catchment in terms of GWS, as detected by the regional hydrological model. Indeed, due to its low resolution, GRACE has shown to provide valuable TWS estimates over regions larger than 200,000 $\mathrm{km}^{2}$ (Longuevergne et al., 2010). As a consequence, GRACE data do not allow to identify rapid and localized water storage variations at the scale of the study area $\left(\sim 5,000 \mathrm{~km}^{2}\right)$. Hydrological regional scale behavior is averaged at larger scales, so GRACE remains useful to study hydrological processes at scales of mountain belts (Chen et al., 2018; Silverii et al., 2016).

An example of an extreme event in North-Eastern Italy is the October 29, 2018, storm Vaia, which produced $>300 \mathrm{~mm}$ of cumulative precipitation in $72 \mathrm{~h}$ and wind gusts exceeding $200 \mathrm{~km} / \mathrm{h}$, causing the loss of 8 million cubic meters of standing trees.

This storm is well recorded as a rapid increase of $\mathrm{GWS}_{\text {res }}$ (dashed line in Figure 4) corresponding to extensional deformation recorded by the GNSS network, with the largest offsets at MGRD ( $\sim 5 \mathrm{~mm}$ toward SE) and BRSE ( 2.5 $\mathrm{mm}$ toward $\mathrm{NW})$.

\section{Hydro-Mechanical Modeling of Water Pressure Distribution}

Transient displacements in the Alps have been interpreted as due to pressure changes associated with water level variations in vertical karst fractures (Devoti et al., 2015; Serpelloni et al., 2018). For the study area, Serpelloni et al. (2018) used a vertical tensile dislocation, in a homogeneous and uniform half space, showing that a similar structure is required to explain the horizontal displacements. However, the simple 
mechanical model proposed in Serpelloni et al. (2018) has limited relationships with the geology and hydrology of the area.

In this work, we develop a two-dimensional finite element model (FEM) with the goal of testing different sources of deformation potentially able to accommodate groundwater pressure changes (GWP) linked to GWS in the Belluno Valley. The physical realism of the different deformation sources is evaluated by comparing modeled surface displacements to the displacement pattern associated with IC2 (Figure 2). The quasi simultaneity of modeled GWS and observed surface displacements (Figure 4) suggests a quasielastic behavior, where water flow and deformation are decoupled. Following Schuite et al. (2017), such behavior would require highly diffusive fractures (i.e., stiff fractures).

We use the "Solid Mechanics" physics module of the COMSOL software (Text S3.1), considering the problem as quasistatic at daily time scales and resolving the model as "stationary." The 2D model (the trace of the profile is shown as a discontinuous line in Figure 3) is defined on the basis of the geological cross section proposed by Galadini et al. (2005). The model is constrained by geological and geophysical information and in agreement with both local seismicity (Danesi et al., 2015; Romano et al., 2019) and seismic prospections (Fantoni et al., 2002). The cross section is normal to the strike of the MCCV mountain range, that is almost parallel to the directions of geodetic displacements associated with IC2 (Figure 2). We use data from the GNSS stations located within a distance of $20 \mathrm{~km}$ from the cross section (considering a length of $\sim 40 \mathrm{~km}$ of the Belluno Valley), whose positions and displacements are projected along the direction of the profile (Figure 5). This analysis is focused on a specific time interval (October 10, 2013 to February 22, 2014; T1 in Figures 2 and 4), corresponding with a period of rapid increase of $\mathrm{GWS}_{\text {res }}$ and extensional deformation (Figure 2).

The FEM model allows us to account for topography and subsurface geological features of the area, like the presence of faults and the different mechanical properties of the rock layers. The rock mechanical parameters used (Table S2), in particular the Young modulus and Poisson's ratio, are taken from Anselmi et al. (2011).

As the model is driven by GWP, a linear relationship with $\mathrm{GWS}_{\mathrm{res}}$ is considered. Different GWP distributions within the mechanical model have been tested, and their physical realism evaluated based on the agreement between model displacements and IC2 spatial pattern (Figure 6). We consider two main families of water pressure distribution:

1) Models where pressure is distributed horizontally and applied vertically on the elastic domain:

Model 1: Water is hosted in the most permeable karst aquifer above the Igne formation, GWP is applied vertically on the aquiclude. Predicted vertical displacements are generally consistent in sign with the observations (Figure S9). On the contrary, horizontal displacements are for most stations opposite in sign compared to observations: compressional deformation is generated instead of an extension.

Model 2a: Similar to Model 1, GWP is focused in the north sector of the anticline, considering the Bassano-Valdobbiadene back thrust as an aquiclude. In this model, water does not accumulate in all the portion of the interface between the Igne formation and the Belluno Basin Units, as assumed in Model 1. Similar to Model 1, predicted horizontal displacements are in all cases in the opposite sense than the IC2-reconstructed ones. Modeled vertical displacements are, with the exclusion of MGRD, in the opposite sense.

Model 2b: Similar to Model 2a, considering the Bassano-Valdobbiadene thrust as an aquiclude. Modeled displacement patterns are similar to Model 2a, with the exception that horizontal displacement at MGRD is in agreement with observations.

Model 2c: The combination of 2a and 2b. Also in this case, the displacement pattern is not well described.

Model 3: Groundwater is stored within the the Belluno Valley, so that water pressure is applied vertically at the surface. While modeled vertical displacements, are consistent in sign with observations (excluding MGRD), horizontal displacements provide a compressional behavior.

2) Models where pressure is distributed vertically along subvertical structures and applied orthogonally in the modeled domain: 


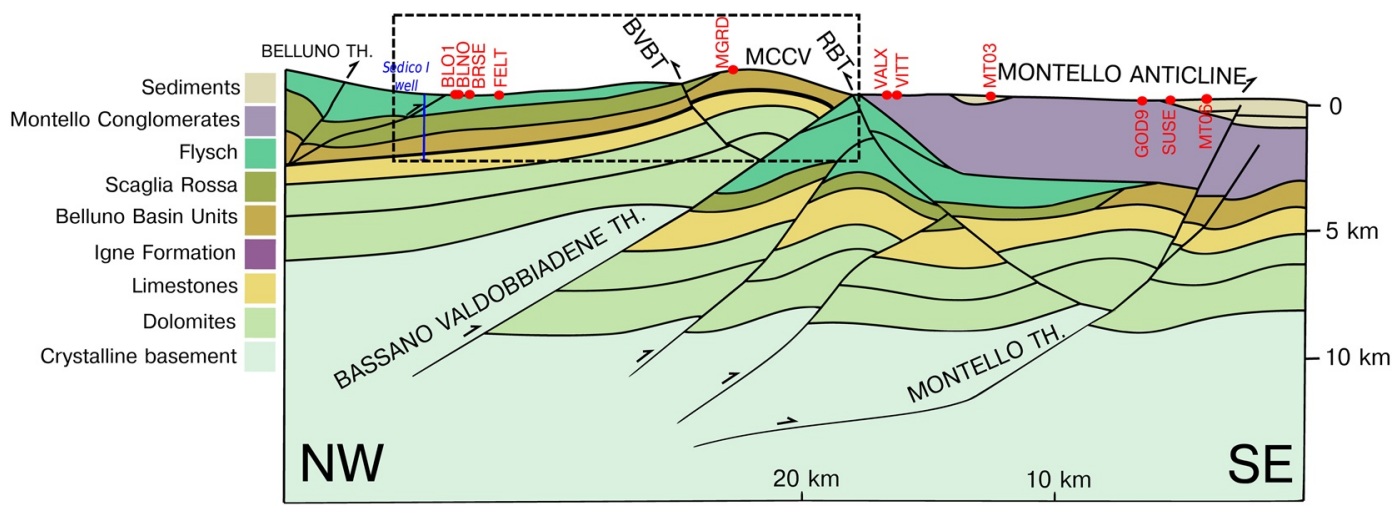

Figure 5. Geological cross section of the study area, modified from (Galadini et al., 2005); red dots: position of the GPS stations projected along this profile. BVBT, Bassano-Valdobbiadene back thrust; RBT, Revine back thrust. The dashed rectangle represents the area shown in Figure 6.

Model 4: The damage zone of the Bassano-Valdobbiadene thrust is considered as highly permeable down to depths where it intersects the impermeable Igne formation. Fault damage zones in the carbonate rocks, in fact, often host open fractures (karst), demonstrating that they can also be conductive to fluid flow (Torabi et al., 2019). GWS translates into GWP, which is applied orthogonally to the fracture walls. Such behavior has been validated in fractured karstic systems in Lesparre et al. (2017). Vertical GWP distribution is defined following Longuevergne et al. (2009), given a preexisting saturated zone: considering $h_{0}$ the initial groundwater height in the fracture, and $h_{1}$ the new height following water level change, $P$ pressure on the fracture walls is constant from the bottom of the fracture up to $h_{0}$ and equals $P=\rho \cdot g \cdot\left(h_{1}-h_{0}\right)$ where $\rho$ is the water density and $g$ the gravity acceleration. In the portion of the fracture above $h_{0}$, the pressure increase on the walls is triangular depends on the water level elevation $(h)$ so that $P=\rho \cdot g \cdot\left(h_{1}-h\right)$. Modeled horizontal displacements matches the observations, except for MGRD station. Vertical displacements are also in good agreement.

Model 5: Similar to Model 4, the open fractured network associated with Bassano-Valdobbiadene back thrust is considered as permeable. Unlike Model 4, all modeled horizontal displacements are well reproduced, including MGRD station.

We use two criteria to evaluate how well a model reproduces the displacements pattern associated with IC2 (Figure 7): the first is the ratio between vertical and horizontal displacement at each GNSS station, which should not significantly exceed 1 ; the second evaluates the spatial distribution, and is computed as the number of stations with the sign of horizontal displacements in agreement in sign with IC2.

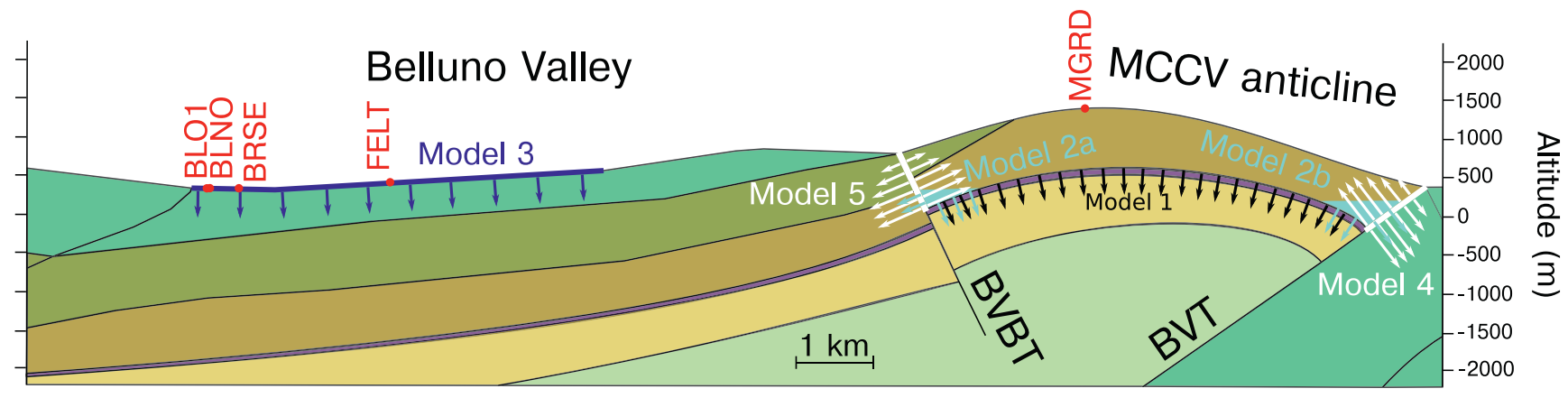

Figure 6. Zoom on the 2D model cross section of Figure 5, showing a schematic representation of the tested models used to explain the horizontal displacements reconstructed by IC2. BVBT, Bassano-Valdobbiadene back thrust; BVT, Bassano-Valdobbiadene thrust; MCCV, Mount Cesen-Col Visentin anticline. Rock formations are shown with the same legend of Figure 5. 

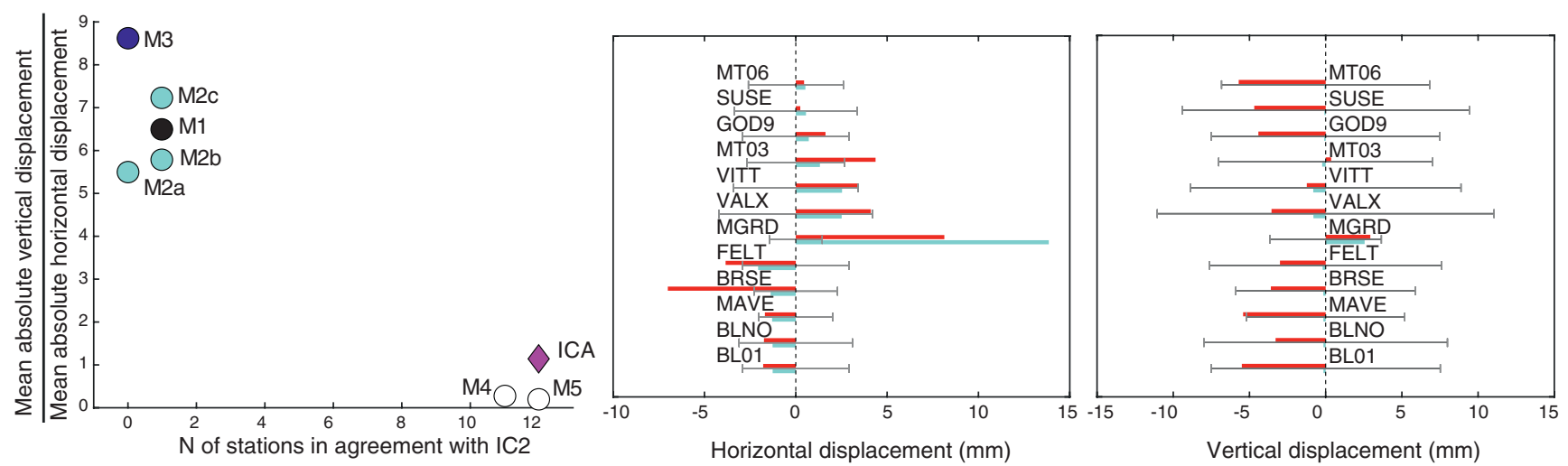

Figure 7. Left: Bi-objective plot describing model ability to describe observations. In the $y$ axis, the ratio between the norm of the vertical and the horizontal displacement; in the $\mathrm{x}$ axis the number of stations with the horizontal displacement pattern in agreement in sign with IC2. The blue diamond "ICA" represents the result of the IC2 reconstruction; the closer a model is to ICA diamond, the better performs. Center and right: horizontal (along N21.5 ${ }^{\circ} \mathrm{W}$ direction) and vertical displacements, reconstructed during T1 period (see Figure 1) by IC2 (red) and computed by the numerical model (blue), using the fracture pressurization from Model 5 and considering a water level increase of $100 \mathrm{~m}$. Horizontal displacement is positive when it is toward SE; vertical displacement is positive when upward. Black bar: mean noise level. Vertical displacement is positive when upward.

According to these criteria, the displacements pattern associated with IC2 is better reproduced by the models where pressure is distributed vertically within permeable fractures than the ones where pressure is distributed horizontally, as clearly highlighted on Figure 7. In fact, the vertical displacements generated by the Models 1, 2, and 3 are too large compared to the horizontal ones, and the horizontal displacements pattern shows significant disagreement with the one associated with IC2 (Figure 2).

The model that best reproduces the horizontal and vertical displacements is Model 5 (Figure 6). Here the fracture is considered hydrologically conductive (Faulkner et al., 2010) down to $0 \mathrm{~m}$ a.s.l where it intersects an impermeable formation (the Igne Formation, see Section 6.1 for details).

We finally analyze the influence of the topography and of the rock stratification on the result obtained by using Model 5. This test is performed by considering both the case where the topography is included but the domain is homogeneous (Model 5a), and the case of a homogeneous domain with a flat free surface. We computed the horizontal and vertical displacements of the three models (Model 5b, Figure S10). We find that there is no significant difference among the three models (i.e., 5, 5a, and 5b) in reproducing the horizontal displacements. The vertical displacements generated by the two models in which the topography is included are very similar (Models 5 and $5 \mathrm{a}$ ), but they differ from the results obtained using a model with a flat free surface (Model 5b). Nonetheless, since the noise level is higher in the vertical component than the horizontal one, the horizontal is considered as the most informative, as discussed in the Text S3.2. Then, topography and layering do not significantly affect the horizontal displacements, while the vertical ones are more affected by the inclusion of the topography than the rock stratification.

\section{Studying the Link Between Hydrology and Seismicity}

In Section 3, we demonstrate the link between GWS and surface deformation (Figure 3), and in Section 4, we provide a physical model explaining this process, linked to the local geological features. In this section, we investigate and test possible relationships between $\mathrm{GWS}_{\text {res }}$ seismicity rates. We use the local earthquake catalog from Romano et al. (2019), which contains high-resolution relocations of 1,609 events with magnitudes ranging from -0.8 to 4.5 , in the period January 2012 to October 2017. This catalog was produced using data from the Collalto Seismic Network (Priolo et al., 2015) and represents one of the most accurate, high quality, earthquake catalogs for this sector of the Southern Alps.

Before exploring any possible link between seismicity rates and hydrological observations, first we calculate the completeness magnitude $\left(M_{c}\right)$, obtaining a value $M_{c}=0.7$ for the full data set; the number of events above $M_{c}$ is 731 (for details see Text S4.1). Afterward, we identify and remove the aftershock events that 
(a)

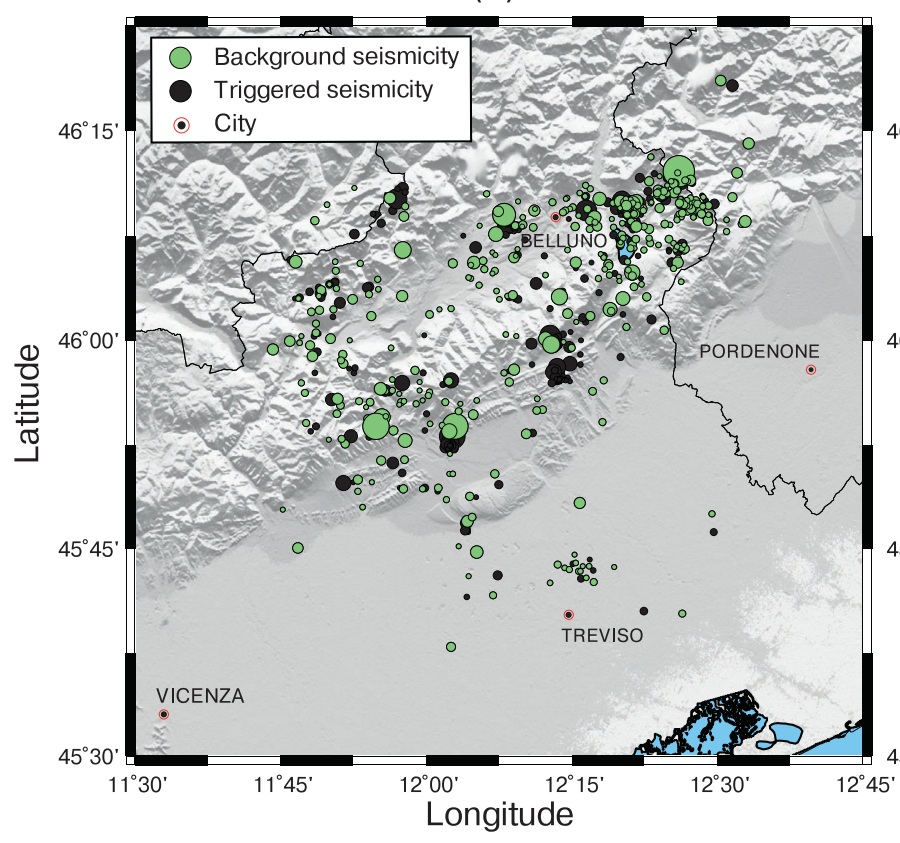

(b)

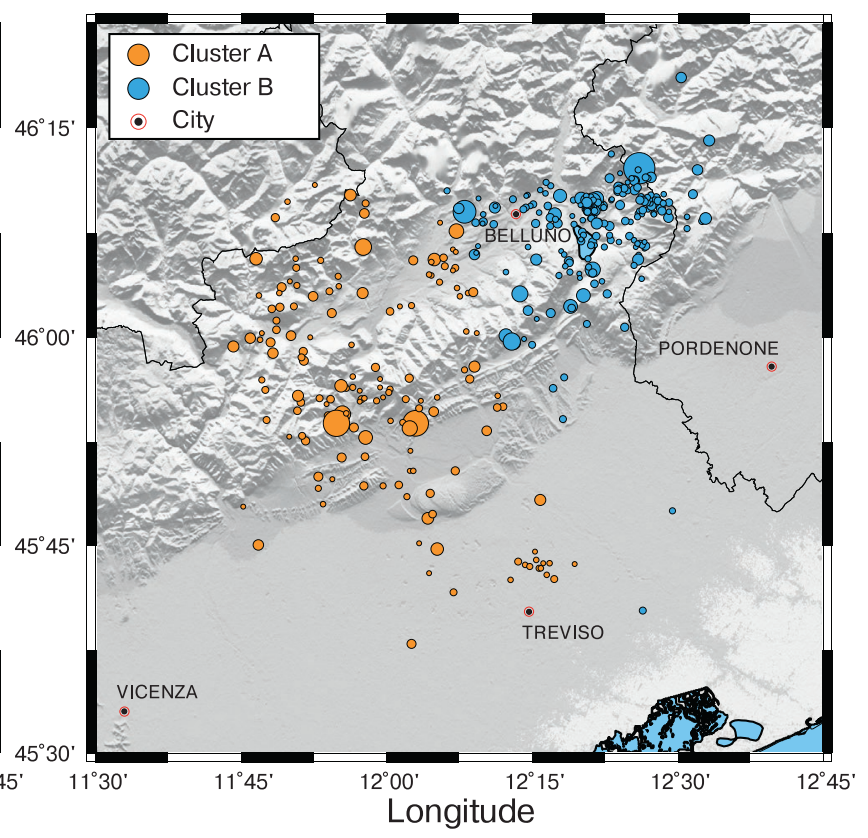

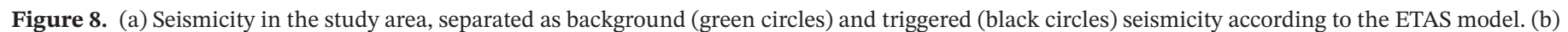
Clusters (A and B) of background seismicity identified using spatial cluster analysis.

are more likely associated with earthquake stress-triggering processes. This analysis is performed by declustering the catalog in the time domain using the epidemic-type aftershock sequences model ETAS (Ogata, 1998). The resulting partition between background seismicity (372 events) and aftershocks ( 359 events) is presented in Figure 8a. The details of the declustering process are presented in the Text S4.1. It is worth noting that, in the ETAS model, the background seismicity is assumed to be generated by a homogeneous Poisson process that is physically associated with a constant-rate tectonic loading process. However, the ETAS-based declustering process does not guarantee that the resulting background seismicity is actually stationary (e.g., Console et al., 2010); as a result, it is actually possible to observe temporal fluctuations in the background seismicity obtained after the temporal declustering process. This departure from stationarity is supposed to be caused by the temporal activation or quiescence of seismic sources forced by processes having a physical cause outside the stationary tectonic loading assumed by ETAS (Zhuang et al., 2002).

In this article, we explore the presence of possible correlations between temporal variations in water storage observations, deformation, and the background seismicity. With this aim, we adopt the covariate model proposed by Garcia-Aristizabal (2018), which allows us to perform a robust statistical evaluation of possible relationships between $\mathrm{GWS}_{\mathrm{res}}\left(x_{\mathrm{GWS}}\right)$ and background seismicity rates. This model has been previously used to study seismicity triggered by underground anthropogenic activity (as e.g., pressurized fluid injections, Garcia-Aristizabal, 2018). The work presented in this article is the first application of this model to study correlations between seismicity and natural forcing processes. According to Garcia-Aristizabal (2018), when the forcing process generating the seismicity in a given zone is stationary in time (as e.g., a constant tectonic loading), the background seismicity rates can be stochastically modeled using a homogeneous Poisson process; it implies that seismicity rates follow the Poisson distribution and, consequently, the times between consecutive events (interevent times, $t_{\mathrm{IET}}$ ) follow the exponential distribution. However, if the forcing process is nonstationary, and if it is possible to identify measurable parameters as proxies of the processes driving such non stationary behavior, then it is possible to model correlations between changes in seismicity rates and changes in the proxy parameters by linking them as covariates of the stochastic model parameters. In order to explore this possibility we set the exponential distribution as the basic template function for modeling the distribution of $t_{\mathrm{IET}}$ : 


$$
f\left(t_{\mathrm{IET}} \mid \mu\left(x_{\mathrm{GWS}}\right)\right)=\frac{1}{\mu\left(x_{\mathrm{GWS}}\right)} \exp \left(\frac{-t_{\mathrm{IET}}}{\mu\left(x_{\mathrm{GWS}}\right)}\right)
$$

and the possible dependencies on hydrological data (in this case $x_{\mathrm{GWS}}$ ) are modeled writing the $\mu$ parameter of the exponential distribution in terms of deterministic functions of $x_{\text {TwS }}$ of the explanatory covariates. $x_{\mathrm{GWS}}$ is measured with respect to a reference $\mathrm{GWS}_{\text {res }}$ assumed to be the minimum value reached by this parameter in the analyzed period. We hypothesize that seismicity rates observed in this zone may be the result of the superposition of a constant rate due to tectonic loading and a seismicity rate perturbation caused by hydrologically driven stress changes. With this aim we test polynomial functions relating $\log (\mu)$ and $x_{\mathrm{GWS}}$ as follows:

$$
\log \left[\mu\left(x_{\mathrm{GWS}}\right)\right]=\sum_{j=0}^{n} \alpha_{j}\left(x_{\mathrm{GWS}}\right)^{j}
$$

where $\alpha_{j}=\left(\alpha_{0}, \alpha_{1}, \ldots, \alpha_{n}\right)$ is a vector of coefficients of the polynomial function relating the $\mu$ parameter of the exponential distribution with the selected covariate $x_{\text {TwS }}$. We study in particular two competing models: (1) the case $n=0$, representing a stationary model (i.e., nondependence on $x_{\mathrm{GWS}}$, and therefore the seismicity rates mainly associated to tectonic loading), and (2) the case $n=1$, representing a log-linear relationship (that is, an exponential relationship between $\mu$ and $x_{\mathrm{GWS}}$ ), which represents the case of seismicity rate resulting from constant tectonic loading ( $\alpha_{0}$ component) modulated by the hydrological processes described by $x_{\mathrm{TWS}}\left(\alpha_{1}\right.$ component). The input data are pairs of $t_{\mathrm{IET}}$ and the respective $x_{\mathrm{GWS}}$ averaged in a $\Delta t$ time window (for which we test different values ranging from days to weeks). The inference of model parameter values is performed using a Markov chain Monte Carlo method, and the selection of the preferred model is performed calculating the Bayes factor, $B_{\mathrm{KL}}$ (Garcia-Aristizabal, 2018). $B_{\mathrm{KL}}$ summarizes the evidence provided by the data in favor of one specific model (K, log-linear model in this application) as opposed to another (L, stationary model in this application): $B_{\mathrm{KL}}<1$ supports the reference model (L), whereas $B_{\mathrm{KL}}>1$ supports the $\mathrm{K}$ competing model (the higher the value, the more evidence in favor of $\mathrm{K}$ ). Additional details on the covariate model, as well as reference values for interpreting $B_{\mathrm{KL}}$ (proposed by Jeffreys, 1961 and Raftery, Table S4) are summarized in Table S4 in the Text S4.2.

The seismicity in the study area is mainly generated as a result of the Adria-Eurasia plate convergence process, accommodated by different, subparallel, thrust faults (Figure 1). In order to quantitatively identify possible spatial sets of seismicity (possibly related to different seismotectonic features), we implement a cluster analysis in the spatial domain (Text S4.3) using the k-means algorithm (MacQueen, 1967); the optimum partition is selected using the Silhouette approach (Rousseeuw, 1987). We find that the background seismicity can be partitioned into two main clusters (Figure 8b): (i) cluster A (orange points), composed by 154 events located in the SW part of the domain, where earthquakes can be associated with the Montello thrust and the BVT faults (Danesi et al., 2015); (ii) cluster B (blue points), composed by 218 events located in the NE part of the domain, in which most of the seismicity can be associated with the N-dipping Cansiglio thrust fault (Galadini et al., 2005; Figure 1b). This preferential cluster partitioning roughly reflects the two main features that we observe in the spatial distribution of the seismicity (Figure 8a): a set of events mostly grouped in the NE part, and a more evenly distributed seismicity toward the SW.

The correlation analysis using the covariate approach is then performed using the data from each spatial cluster of background seismicity. Comparing plots of the moving average of both $\mathrm{GWS}_{\mathrm{res}}$ and the rate of seismic events (calculated in 90-days length time windows sliding at increments of 1 day) for cluster A (Figure 9a) and cluster B (Figure 9b), we observe that only the seismicity rate in cluster A tends to change in agreement with the changes in the $\mathrm{GWS}_{\text {res }}$. This qualitative observation is quantitatively confirmed by the covariate analysis: the $B_{\mathrm{KL}}$ indicates that only for cluster A, which is associated with the Montello thrust and the BVT faults, the nonstationary model performs better than the alternative stationary solution $\left(B_{\mathrm{KL}}=5.24\right)$. This value supports a log-linear relationship between the seismicity rate (modeled through the distribution of interevent times, $t_{\mathrm{IET}}$ ) and the $\mathrm{GWS}_{\text {res }}$ (Figure 9c). On the contrary, for cluster B, the evidence supports the stationary model $\left(B_{\mathrm{KL}}=0.57\right.$, Figure $\left.9 \mathrm{~d}\right)$, indicating a not significant (or not identifiable) link between seismicity rates in the Cansiglio thrust fault zone and $\mathrm{GWS}_{\text {res }}$ in the Belluno Valley. The parameter 


\section{Cluster A}

(a)

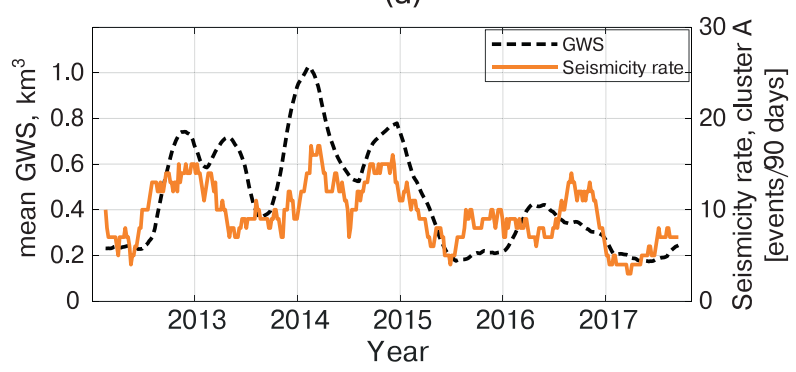

(c)

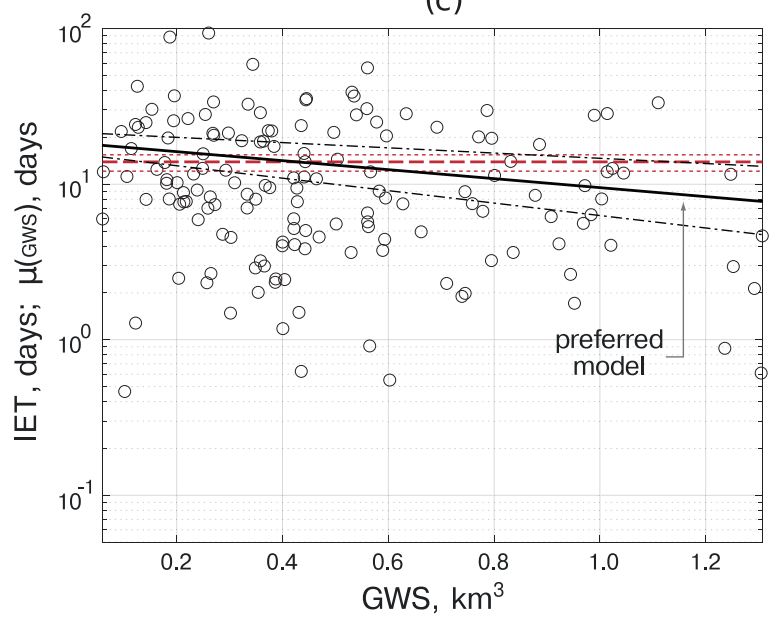

Cluster B

(b)

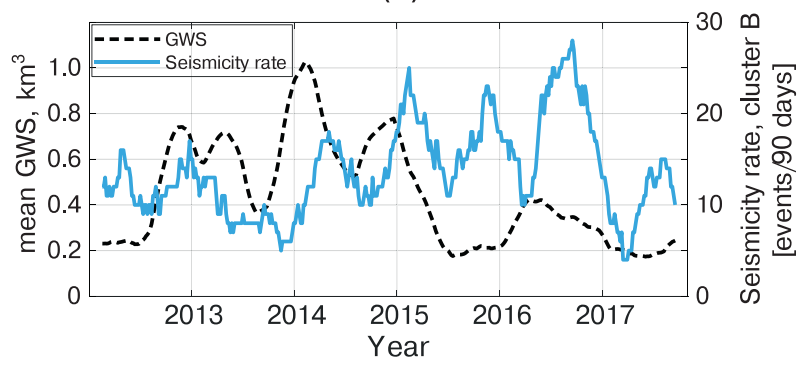

(d)

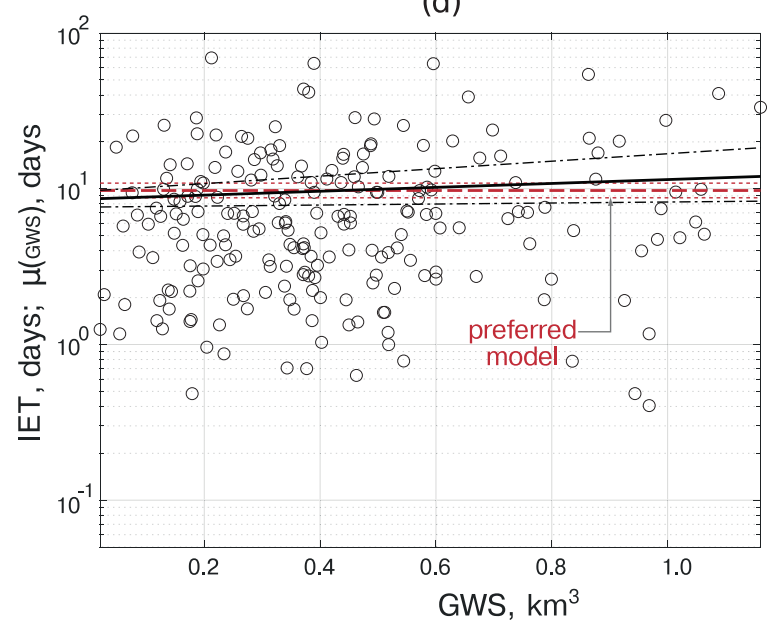

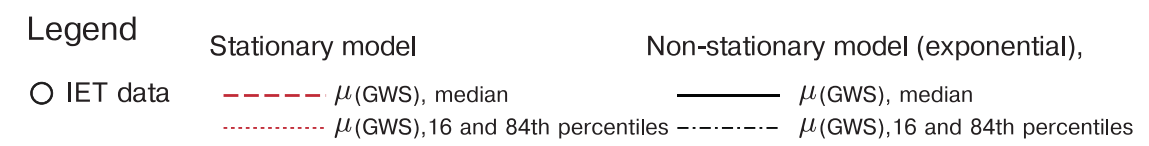

Figure 9. Moving average GWS (discontinuous black) and rate of seismic events in (a) cluster A (continuous orange) and (b) cluster B (continuous blue),

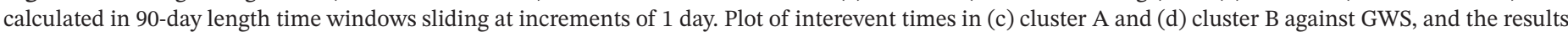
for the two tested models: stationary model (red) and Log-linear (black). Preferred models are indicated with the arrow in (c and d).

Table 1

Model Parameter Values Obtained for the Competing Models Tested for Assessing Possible Relationships Between Seismicity Rates and GWS res According to Equation 4 (Stationary: $\log \left[\mu\left(x_{T W S}\right)\right]=\alpha_{0} ;$ Log-Linear: $\log$ $\left.\left[\mu\left(x_{T W S}\right)\right]=\alpha_{0}+\alpha_{1} x_{T W S}\right)$

\begin{tabular}{lll}
\hline & $\begin{array}{c}\text { Competing } \\
\text { models } \\
\text { from }\end{array}$ & \multicolumn{1}{c}{$\begin{array}{c}\text { Parameter values median (16th, 84th } \\
\text { percentiles) }\end{array}$} \\
Data set & Equation 4: & \multicolumn{1}{c}{ (1.11,18) } \\
Cluster A & Stationary & $\alpha_{0}=1.14\left(1.11, \alpha_{1}=-0.29(-0.41,-0.17)\right.$ \\
& Log-linear & $\alpha_{0}=1.28(1.21,1.35) ; \alpha_{1}$ \\
Cluster B & Stationary & $\alpha_{0}=0.99(0.96,1.02)$ \\
& Log-linear & $\alpha_{0}=0.93(0.88,0.99) ; \alpha_{1}=0.12(0.03,0.23)$ \\
\hline
\end{tabular}

Note. The preferred model in each case is highlighted in bold. values of the fitted models are summarized in Table 1. As it can be seen in Table 1, for cluster $\mathrm{A} \alpha_{1}=-0.29$; this negative slope in the preferred log-linear model implies that $\mathrm{GWS}_{\text {res }}$ modulates seismicity so that the higher the GWS $\mathrm{G}_{\text {res}}$, the shorter the mean $t_{\mathrm{IET}}$ (and therefore the higher the seismicity rate). It is worth noting that our analysis does not identify a link between GWS $_{\text {res }}$ and the seismicity rates in cluster B. We cannot discern whether this result is related to an actual missing link between these two processes or a consequence of limitations in both methods and available data. In our opinion, both possibilities are plausible. A reasonable explanation for an eventual missing link between these two processes is that cluster B is located relatively far from the modeled source of deformation; consequently, the magnitude of the stress perturbation for this area (caused by the modeled deformation source) is smaller than the stress perturbation in the zone where cluster $\mathrm{A}$ is located (which is closer to the deformation source). 


\section{Discussion}

\subsection{Hydromechanical Coupling}

In Sections 3 and 4, we describe the link between hydrological processes and solid Earth deformation by the joint interpretation of results from hydrological and mechanical models constrained by geodetic, hydrological, meteorological observations, and geological/geophysical information on subsurface structural and tectonic settings. The high ratio between horizontal and vertical displacements (Figure 7), suggests that the most likely mechanism able to produce the horizontal, anisotropic, extensional deformation, observed during a phase of large water storage increase, is GWP in narrow, subvertical, permeable geological structures. The same mechanism is assumed to be able to explain smaller deformation associated with phases of smaller $\mathrm{GWS}_{\text {res }}$ increase, and, with inverted sign, to explain the observed compressional deformation during phases of GWS $\mathrm{G}_{\text {res }}$ decrease, responding to the fast dynamics of karst systems, including extreme events (e.g., the 2018 Vaia storm).

We identify the back thrust associated with the Bassano-Valdobbiadene thrust fault as the main source of deformation. We assume that the network of damage-zone faults, which is modeled as a single fracture associated with BVBT (i.e., Model 5), are well connected, saturated and that GWP varies as the GWS res, generating pressure changes orthogonal to fracture walls.

A precise description of the source of deformation, which includes the identification of both the fracture bottom position and the water level rise inside it, is not straightforward because of the trade-off between fracture width and its opening (e.g., Devoti et al., 2015; Longuevergne et al., 2009; Silverii et al., 2016). For geological reasons, we assume the bottom position of the fracture at $0 \mathrm{~m}$ above sea level, at the interface between the Vajont limestone and the more impermeable Igne formation (see Figure 6). The water level rise providing the best match between modeled and observed displacements is $100 \mathrm{~m}$ (Figure 7). This large value seems realistic; for example, maximum water level variation measured in a similar karst system is $\sim 300 \mathrm{~m}$ (Milanovic, 2005). The static water level inside the fracture is set at $700 \mathrm{~m}$ above sea level during drought periods, so that it increases by $100 \mathrm{~m}$ up to $10 \mathrm{~m}$ below topography when $\mathrm{V} 2$ reaches its maximum during the analyzed time-period (i.e., January, 2014).

Furthermore, we analyze the effect of the initial opening of the fracture when applying the same pressure values on its walls, finding that assuming different initial opening values does not impact significantly the resulting displacements (Figure S11). As a consequence, the volumes of water involved cannot be quantified, since the only quantity affecting the displacements is the water level variation, while the initial fracture opening does not play a key role.

The transformation of rainfall into GWS raises the question on how the aquifer connected to the BVBT fracture is recharged. It is likely that the water feeding the fracture mainly comes from the top of the MCCV mountain chain: the higher fracture density at the hinge zone of the anticline (e.g., Feng \& Gu, 2017) and the well-developed epikarst in the exposed rock formations (Maiolica and Rosso Ammonitico) suggest the presence of an epikarst circulation on the top of MCCV chain (Klimchouk \& Sauro, 1996). The combined effect of the epikarst and the presence of a shallow, low permeable layer (the Fonzaso formation, located at $200 \mathrm{~m}$ of depth from the surface) facilitates the rapid infiltration of precipitation water and its convergence flow toward the back thrust, following the northward inclination of rock layers and stratification. However, we cannot exclude that water can flow southward, toward the BVT, which might behave similarly to the back thrust as an hydrologically active structure, at lower dip (Text S3.2, Model 4). Nonetheless, the site MGRD (Figure 1a) moves toward the BVT and away from the back thrust when GWS $_{\text {res }}$ increases, implying that the role of the $30^{\circ}$ dipping BVT, as a hydrologically active structure, is likely to have a secondary effect with respect to its back thrust.

Furthermore, the transformation of GWS into GWP and then into deformation assumes the diffusion of pressure in the saturated part of the BVBT fracture down to the fracture root depth. If GWS were instantaneously transformed into pressure, the diffusivity of the fracture would be infinite. Instead, the cross-correlation between GWS and deformation would suggest a time shift of the order of 2 days (see Section 3). Following (Schuite et al., 2017), the BVBT fracture diffusivity $D$ can be estimated as $D=L^{2} / \tau$, where $L$ is the length of the saturated part of the BVBT fracture, from water height down to fracture root $(\sim 800 \mathrm{~m})$ and 
$\tau$ the characteristic time (i.e., the time shift between GWS and V2). Estimated diffusivity $\left(\sim 4 \mathrm{~m}^{2} / \mathrm{s}\right)$ lies in the high range of observed values, suggesting a stiff fracture, but of the same order of magnitude in similar contexts (D'Agostino et al., 2018; Hainzl et al., 2006).

Given the spatial distribution and density of available geodetic data, the 2D numerical model used in this work can be considered as an acceptable simplification. However, we are aware of its limitations. We are assuming that geological features (including, for example, outcropping formations, fracture spacing, strike of faults and fractures, topography) are constant along the SW-NE direction, for about $40 \mathrm{~km}$, which is not necessarily true. A 2D model cannot take into account the fact that the MCCV mountain chain and associated thrust and back thrust faults curve north, going into the N-S trending Fadalto valley (see Figure 1). More importantly, changes in water level along the back thrust are implicitly assumed to be uniform along its strike in a 2D model, but a heterogeneous change in water level can cause more localized deformation signals, which would be however difficult to detect with the present GNSS network configuration. Moreover, effects associated with similar processes occurring at nearby karst systems cannot be taken into consideration. Hydrological deformation in the Cansiglio plateau, in fact (Devoti et al., 2015; Serpelloni et al., 2018) may affect GNSS sites VITT and GOD9 (Figure 1).

\subsection{Seismotectonic Implications}

Two main mechanisms have been suggested to explain hydrological modulation of seismicity: variations in pore-fluid pressure at hypocentral depths (Hainzl et al., 2006) and direct stress on the fault plane (Bettinelli et al., 2008; Craig et al., 2017; D'Agostino et al., 2018; Johnson et al., 2017). In the latter case, there is usually a little or no time delay between hydrological indicators and seismicity rate. In the former, seismicity rate variations are usually delayed with respect to hydrological observations by a time lag, which is strictly dependent on the earthquake nucleation depth and on the hydraulic diffusivity of the material between the surface and the seismic source. The lack of temporal delay between the seismicity rate and the GWS (Figure 9a) excludes an important role for poroelastic processes.

Pore pressure propagation might play a role in the case of shallow earthquakes, whose hypocenters are close to the depth reached by the water flowing as "fast flow" in highly permeable fractures. Nonetheless, it is unlikely that this kind of fractures can reach depths larger than $2 \mathrm{~km}$. It follows that the pore pressure pulse would take several days to reach the depths where most of the seismicity is located ( $>6 \mathrm{~km})$, so that we would observe a significant time delay between seismicity rates and GWS changes. According to Costain (2008; see Figure 7), using a diffusivity value of $4 \mathrm{~m}^{2} / \mathrm{s}$, as we estimated in Section 6.1, the pore pressure pulse would take about 60 days to reach a depth of $10 \mathrm{~km}$.

The most likely process linking hydrology and seismicity is then the direct effect of stress changes at seismogenic depths. In case of seasonal stress perturbations, seismicity rates can correlate either with the stress values or with stress rates, depending if the period of the stress perturbation $\left(T_{p}\right)$ is smaller or larger than a critical period $\left(T_{a}\right)$, which in turn is controlled by the loading plate velocity (Ader et al., 2014). The period that dominates the temporal evolution of stress in the study area is 1 year (Figure S7), which is a value that $T_{a}$ reaches only in rapidly deforming regions (Bettinelli et al., 2008). In slowly deforming regions, such as the Southern Alps, $T_{a}$ usually assumes larger values. This observation is consistent with our findings, implying that stress changes are proportional to the magnitude of the $\mathrm{GWS}_{\text {res }}$ and not to its time derivative (which represents whether $\mathrm{GWS}_{\text {res }}$ is in an increasing or decreasing phase).

We estimate the stress change associated with the deformation caused by the water pressure increase (T1 time window in Figure 4) in the hypothesized fracture source. In practice, we calculate the Coulomb failure function (CFF, Text S3.3) on receiving planes oriented in agreement with the compressional tectonic regime of the area. Figure 10a shows CFF values obtained assuming a shallow-dipping $\left(10^{\circ}\right)$ decollement (i.e., the Montello flat) as receiving source, showing that in the depth interval where most of the seismicity associated with cluster A (see Figure $8 \mathrm{~b}$ ) is located (4-14 km), positive stress changes may be as large as $25 \mathrm{kPa}$ (10 kPa in the Montello flat). Considering that the stressing rates from tectonic loading are expected to be of the order of 1-3 kPa/yr (Caporali et al., 2018), during T1 the hydrological stress increase is 30 times larger than the tectonic one. Similar values are obtained, but with different spatial patterns, assuming different 

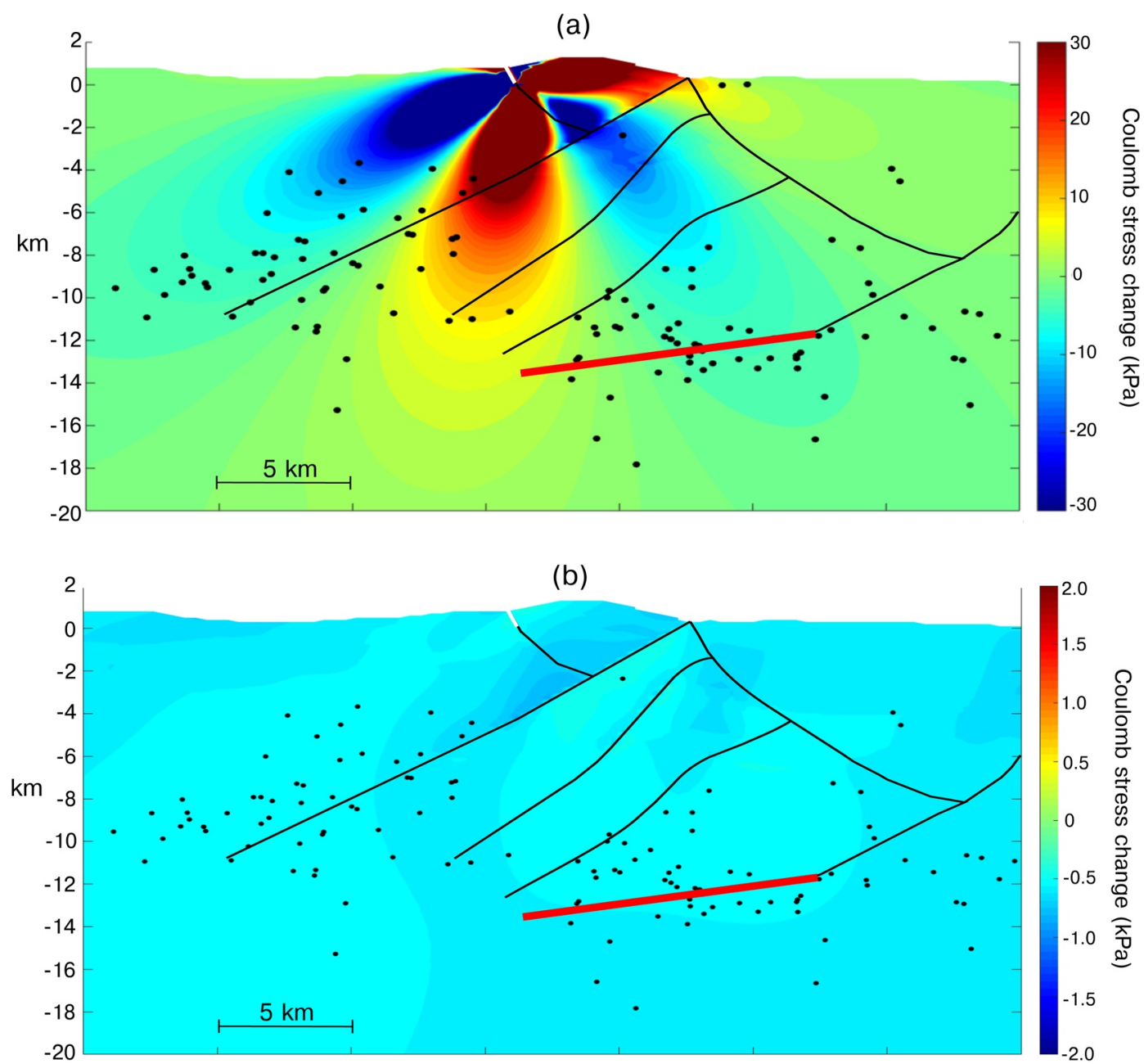

Figure 10. (a) Coulomb stress change during a phase of $\mathrm{GWS}_{\text {res }}$ increase (T1 in Figure 4) caused by a source of deformation as in Model 5 (see Text S3.2), considering planes parallel to the Montello decollement (dip angle $=10^{\circ}$ ), highlighted in red. (b) Coulomb stress change calculated on the same dipping planes considering as source of deformation a $1 \mathrm{kPa}$ uniform load on the free surface. This value causes a subsidence of $\sim 3.8 \mathrm{~mm}$, which is consistent with the amplitude of the vertical displacements caused by the large scale superficial loading in the time interval that goes from summer to winter (see Figure 2) and inhibits thrust faulting (negative CFF values in all the domain). The black dots represent the background seismicity of cluster A.

thrust-receiving sources; however, a spatial correlation between areas of stress increase and background seismicity is not evident. However, it is worth considering that the faulting mechanisms of the background seismicity are not well constrained, and the focal mechanisms available for the events in the catalog of Romano et al. (2019), or other studies (e.g., Anselmi et al., 2011), show a large range of mechanisms, including normal, thrust and strike-slip faulting on different planes. Therefore, while a clear spatial correlation between seismicity and regions of positive stress increase is not apparent, it is likely that the highly deformed upper crust, inherited by the complex tectonic evolution of the Southern Alps (Castellarin \& Cantelli, 2000), provides heterogeneous response to the hydrologically modulated stress changes. Another important factor possibly playing a role in the apparent missing fit between seismicity locations and stress increase are the uncertainties in earthquake locations. Uncertainties in the location of small earthquakes are usually large; the formal errors reported with earthquake locations are mostly based on uncertainties on seismic-phase arrival time measurements that in general give unrealistic small mislocation errors with respect to what is observed when other sources of uncertainty (as e.g., modeling errors related to travel time calculations and the nonlinearity of the location problem) are considered (see e.g., Garcia-Aristizabal et al., 2020). Moreover, 
the stress change modeling is performed in a 2D domain, making less reliable a comparison between earthquake locations and positive Coulomb stress changes.

It is however important to note that the amplitude of the CFF field generated by the $\mathrm{GWS}_{\text {res }}$ increase in hydrologically active fracture is much larger than the one generated by the annual surface hydrological mass loading (Figure 10b), which actually is considered as the main mechanism that modulates seismicity rates in other regions (Craig et al., 2017; Johnson et al., 2017), where much greater annual vertical displacements, and consequently greater seasonal stress perturbations than those observed in the Alps, are present. We finally point out that, as shown in Figure S12, the topography and geological features of the domain do not significantly affect the CFF patterns.

\section{Conclusions}

Using geodetic and environmental data, integrated into hydrological and mechanical models, we show how groundwater convergence toward a specific zone can generate horizontal surface displacements that are superimposed to annual surface hydrological loading and horizontal, linear, tectonic loading. We find that the background seismicity of a spatial cluster distributed across the fold-and-thrust belt is correlated with the temporal evolution of water storage changes. Although the limited spatial and temporal extent of the earthquake catalog will require future analyses to support this conclusion. Hydraulic pressure changes in a shallow hydrologically active fracture $(<1 \mathrm{~km})$ can generate large shears $(\sim 10 \mathrm{kPa})$ in faults oriented orthogonally and at distances of the order of $\sim 10 \mathrm{~km}$ (horizontally and vertically). A highly deformed upper crust may be responsible for an heterogeneous response to the hydrologically modulated stress changes. The link between hydrology, deformation and seismicity may be favored by (1) the existence of a (shallow) subvertical hydrologically active fracture connected to the surface, (2) water convergence from a watershed/ river basin toward the hydrologically active structure, leading to large water storage (and therefore water pressure) changes, and (3) the existence of properly oriented (orthogonal), seismically active structures (such as a classical thrust/back thrust couple). In such contexts, horizontal deformation is best suited to highlight physical links between surface deformation and hydro-mechanical processes occurring at depth. An ongoing effort to improve the deformation monitoring by extending the GNSS network will allow developing more complex 3D models, while using seismic catalogs spanning longer time-intervals will help to better explore the significance of the relationship between hydrology and seismicity found in this work. Finally, current seismic noise monitoring activities have been proved effective in providing additional constraints on groundwater mapping (Clements \& Denolle, 2018); then this technique will be soon applied in this region.

\section{Data Availability Statement}

Precipitation, temperature, and river flow data are provided by "Agenzia Regionale per la Prevenzione e Protezione Ambientale del Veneto” (ARPAV): https://www.arpa.veneto.it/bollettini/storico/Mappa_2019_ TEMP.htm. Extraterrestrial irradiance data are available from http://www.soda-pro.com/web-services/ radiation/extraterrestrial-irradiance-and-toa. Drainage direction maps used to define river basins are available on www.hydrosheds.org/page/availability. The analyzed seismic catalog is available in the supplementary material of Romano et al. (2019). We use publicly available raw GNSS data. However, RINEX data can be requested from authors, if not yet available on the original repositories. Raw GPS time series are available on https://doi.org/10.1594/PANGAEA.912895. The Collalto Seismic Network data are available on https://doi.org/10.7914/SN/EV. GRACE EWT data: D. N. Wiese, D.-N. Yuan, C. Boening, F. W. Landerer, M. M. Watkins. 2019. JPL GRACE and GRACE-FO Mascon Ocean, Ice, and Hydrology Equivalent Water Height JPL Release 06 Version 02. Ver. 2. PO.DAAC, CA, USA. Data set accessed [2020-0429] at https://doi.org/10.5067/TEMSC-3MJ62. The MATLAB code for GWS estimation is available from http://dx.doi.org/10.17632/m5p5xmrr7k.1. The MATLAB code for vbICA decomposition is available from http://dx.doi.org/10.17632/n92vwbg8zt.1. 
Acknowledgments

We thank L. Anderlini for helpful discussions and suggestions on stress analysis and E. Scoccimarro for suggestions on the analysis of pluviometric data. This work and F. Pintori are supported by the project TRANSIENTI, founded by the Italian Ministry of Education, Universities and Research (MIUR) "Premiale 2014." L. Longuevergne acknowledges the support of SNO H+ and OZCAR Research Infrastructure.

\section{References}

Ader, T. J., Lapusta, N., Avouac, J.-P., \& Ampuero, J.-P. (2014). Response of rate-and-state seismogenic faults to harmonic shear-stress perturbations. Geophysical Journal International, 198, 385-413. https://doi.org/10.1093/gji/ggu144

Anderlini, L., Serpelloni, E., Tolomei, C., De Martini, P. M., Pezzo, G., Gualandi, A., \& Spada, G. (2020). New insights into active tectonics and seismogenic potential of the Italian Southern Alps from vertical geodetic velocities. Solid Earth, 11, 1681-1698. https://doi. org/10.5194/se-11-1681-2020

Andermann, C., Longuevergne, L., Bonnet, S., Crave, A., Davy, P., \& Gloaguen, R. (2012). Impact of transient $\mathrm{n}$ storage on the discharge of Himalayan rivers. Nature Geoscience, 5, 127-132. https://doi.org/10.1038/ngeo1356

Anselmi, M., Govoni, A., De Gori, P., \& Chiarabba, C. (2011). Seismicity and velocity structures along the south-Alpine thrust front of the Venetian Alps (NE-Italy). Tectonophysics, 513, 37-48. https://doi.org/10.1016/j.tecto.2011.09.023

Bettinelli, P., Avouac, J.-P., Flouzat, M., Bollinger, L., Ramillien, G., Rajaure, S., \& Sapkota, S. (2008). Seasonal variations of seismicity and geodetic strain in the Himalaya induced by surface hydrology. Earth and Planetary Science Letters, 266, 332-344. https://doi. org/10.1016/j.epsl.2007.11.021

Borsa, A. A., Agnew, D. C., \& Cayan, D. R. (2014). Remote hydrology. Ongoing drought-induced uplift in the western United States. Science, 345, 1587-1590. https://doi.org/10.1126/science.1260279

Caporali, A., Braitenberg, C., Montone, P., Rossi, G., Valensise, G., Viganò, A., \& Zurutuza, J. (2018). A quantitative approach to the loading rate of seismogenic sources in Italy. Geophysical Journal International, 213, 2096-2111. https://doi.org/10.1093/gji/ggy112

Castellarin, A., \& Cantelli, L. (2000). Neo-Alpine evolution of the Southern Eastern Alps. Journal of Geodynamics, 30, 251-274. https:// doi.org/10.1016/S0264-3707(99)00036-8

Chanard, K., Avouac, J. P., Ramillien, G., \& Genrich, J. (2014). Modeling deformation induced by seasonal variations of continental water in the Himalaya region: Sensitivity to Earth elastic structure. Journal of Geophysical Research: Solid Earth, 119, 5097-5113. https://doi. org/10.1002/2013JB010451

Chanard, K., Fleitout, L., Calais, E., Barbot, S., \& Avouac, J.-P. (2018). Constraints on transient viscoelastic rheology of the asthenosphere from seasonal deformation. Geophysical Research Letters, 45, 2328-2338. https://doi.org/10.1002/2017GL076451

Chan, K., Lee, T.-W., \& Sejnowski, T. J. (2003). Variational Bayesian learning of ICA with missing data. Neural Computation, 15, 1991-2011. https://doi.org/10.1162/08997660360675116

Chen, W., Braitenberg, C., \& Serpelloni, E. (2018). Interference of tectonic signals in subsurface hydrologic monitoring through gravity and GPS due to mountain building. Global and Planetary Change, 167, 148-159. https://doi.org/10.1016/j.gloplacha.2018.05.003

Clements, T., \& Denolle, M. A. (2018). Tracking groundwater levels using the ambient seismic field. Geophysical Research Letters, 45(13), 6459-6465. https://doi.org/10.1029/2018GL077706

Console, R., Jackson, D. D., \& Kagan, Y. Y. (2010). Using the ETAS model for catalog declustering and seismic background assessment. Pure and Applied Geophysics, 167, 819-830. https://doi.org/10.1007/s00024-010-0065-5

Costain, J. K. (2008). Intraplate seismicity, hydroseismicity, and predictions in hindsight. Seismological Research Letters, 79(4), 578-589. https://doi.org/10.1785/gssrl.79.4.578

Craig, T. J., Chanard, K., \& Calais, E. (2017). Hydrologically-driven crustal stresses and seismicity in the New Madrid Seismic Zone. Nature Communications, 8, 2143. https://doi.org/10.1038/s41467-017-01696-w

Danesi, S., Pondrelli, S., Salimbeni, S., Cavaliere, A., Serpelloni, E., Danecek, P., et al. (2015). Active deformation and seismicity in the Southern Alps (Italy): The Montello hill as a case study. Tectonophysics, 653, 95-108. https://doi.org/10.1016/j.tecto.2015.03.028

de Lavenne, A., Thirel, G., Andréassian, V., Perrin, C., \& Ramos, M.-H. (2016). Spatial variability of the parameters of a semi-distributed hydrological model. Proceedings of the International Association of Hydrological Sciences, 373, 87-94. https://doi.org/10.5194/ piahs-373-87-2016

Devoti, R., Zuliani, D., Braitenberg, C., Fabris, P., \& Grillo, B. (2015). Hydrologically induced slope deformations detected by GPS and clinometric surveys in the Cansiglio Plateau, southern Alps. Earth and Planetary Science Letters, 419, 134-142. https://doi.org/10.1016/j. epsl.2015.03.023

Drouin, V., Heki, K., Sigmundsson, F., Hreinsdóttir, S., \& Ófeigsson, B. G. (2016). Constraints on seasonal load variations and regional rigidity from continuous GPS measurements in Iceland, 1997-2014. Geophysical Journal International, 205, 1843-1858. https://doi. org/10.1093/gji/ggw122

D'Agostino, N., Silverii, F., Amoroso, O., Convertito, V., Fiorillo, F., Ventafridda, G., \& Zollo, A. (2018). Crustal deformation and seismicity modulated by groundwater recharge of karst aquifers. Geophysical Research Letters, 45, 12253-12262. https://doi. org/10.1029/2018GL079794

Famiglietti, J. S., Lo, M., Ho, S. L., Bethune, J., Anderson, K. J., Syed, T. H., et al. (2011). Satellites measure recent rates of groundwater depletion in California's Central Valley. Geophysical Research Letters, 38, L03403. https://doi.org/10.1029/2010GL046442

Fantoni, R., Catellani, D., Merlini, S., Rogledi, S., \& Venturini, S. (2002). La registrazione degli eventi deformativi cenozoici nell'avampaese Veneto-Friulano. Memorie della Societa Geologica Italiana, 57, 301-313.

Faulkner, D. R., Jackson, C. A. L., Lunn, R. J., Schlische, R. W., Shipton, Z. K., Wibberley, C. A. J., \& Withjack, M. O. (2010). A review of recent developments concerning the structure, mechanics and fluid flow properties of fault zones. Journal of Structural Geology, 32, 1557-1575. https://doi.org/10.1016/j.jsg.2010.06.009

Feng, J., \& Gu, K. (2017). Geomechanical modeling of stress and fracture distribution during contractional fault-related folding. Journal of Geoscience and Environment Protection, 05, 61-93. https://doi.org/10.4236/gep.2017.511006

Filippini, M., Squarzoni, G., De Waele, J., Fiorucci, A., Vigna, B., Grillo, B., et al. (2018). Differentiated spring behavior under changing hydrological conditions in an alpine karst aquifer. Journal of Hydrology, 556, 572-584. https://doi.org/10.1016/j.jhydrol.2017.11.040

Fu, Y., Argus, D. F., Freymueller, J. T., \& Heflin, M. B. (2013). Horizontal motion in elastic response to seasonal loading of rain water in the Amazon Basin and monsoon water in Southeast Asia observed by GPS and inferred from GRACE. Geophysical Research Letters, 40, 6048-6053. https://doi.org/10.1002/2013GL058093

Galadini, F., Poli, M.E., \& Zanferrari, A. (2005). Seismogenic sources potentially responsible for earthquakes with $M \geq 6$ in the eastern Southern Alps (Thiene-Udine sector, NE Italy). Geophysical Journal International, 161, 739-762. https://doi.org/10.1111/j.1365-246X.2005.02571.x

Garcia-Aristizabal, A. (2018). Modelling fluid-induced seismicity rates associated with fluid injections: examples related to fracture stimulations in geothermal areas. Geophysical Journal International, 215, 471-493. https://doi.org/10.1093/gji/ggy284

Garcia-Aristizabal, A., Danesi, S., Braun, T., Anselmi, M., Zaccarelli, L., Famiani, D., \& Morelli, A. (2020). Epistemic uncertainties in local earthquake locations and implications for managing induced seismicity. Bulletin of the Seismological Society of America, 110, 2423-2440. https://doi.org/10.1785/0120200100 
Gegout, P., Boy, J. P., Hinderer, J., \& Ferhat, G. (2010). Modeling and observation of loading contribution to time-variable GPS sites positions. In S. P. Mertikas (Ed.), Gravity, geoid and Earth observation: IAG Commission 2: Gravity field, Chania, Crete, Greece, 23-27 June 2008, International Association of Geodesy Symposia (pp. 651-659). Berlin, Heidelberg: Springer. https://doi.org/10.1007/978-3-642-10634-7_86

Gualandi, A., Nichele, C., Serpelloni, E., Chiaraluce, L., Anderlini, L., Latorre, D., et al. (2017). Aseismic deformation associated with an earthquake swarm in the northern Apennines (Italy). Geophysical Research Letters, 44, 7706-7714. https://doi.org/10.1002/2017GL073687

Gualandi, A., Perfettini, H., Radiguet, M., Cotte, N., \& Kostoglodov, V. (2017). GPS deformation related to the Mw 7.3, 2014, Papanoa earthquake (Mexico) reveals the aseismic behavior of the Guerrero seismic gap. Geophysical Research Letters, 44, 6039-6047. https:// doi.org/10.1002/2017GL072913

Gualandi, A., Serpelloni, E., \& Belardinelli, M. E. (2016). Blind source separation problem in GPS time series. Journal of Geodesy, 90, 323-341. https://doi.org/10.1007/s00190-015-0875-4

Hainzl, S., Kraft, T., Wassermann, J., Igel, H., \& Schmedes, E. (2006). Evidence for rainfall-triggered earthquake activity. Geophysical Research Letters, 33, L19303. https://doi.org/10.1029/2006GL027642

Jeffreys, H. (1961). Theory of probability (3rd ed.). Oxford, England: Oxford university press.

Jensen, M. E., Burman, R. D., \& Allen, R. G. (1990). Evapotranspiration and irrigation water requirements (ASCE Manuals and Reports on Engineering Practices No. 70, p. 360). New York, NY: American Society of Civil Engineers.

Johnson, C. W., Fu, Y., Bürgmann, R. (2020). Hydrospheric modulation of stress and seismicity on shallow faults in southern Alaska. Earth and Planetary Science Letters, 530, 115904. http://dx.doi.org/10.1016/j.epsl.2019.115904.

Johnson, C. W., Fu, Y., \& Bürgmann, R. (2017). Seasonal water storage, stress modulation, and California seismicity. Science, 356, 11611164. https://doi.org/10.1126/science.aak9547

Klimchouk, A. B., \& Sauro, U. (1996). "Hidden" shafts at the base of the epikarstic zone: A case study from the Sette Communi plateau, Venetian Pre-Alps, Italy. Cave and Karst Science, 23, 101-107.

Kositsky, A. P., \& Avouac, J. P. (2010). Inverting geodetic time series with a principal component analysis-based inversion method. Journal of Geophysical Research, 115, B03401. https://doi.org/10.1029/2009JB006535

Lesparre, N., Boudin, F., Champollion, C., Chéry, J., Danquigny, C., Seat, H. C., et al. (2017). New insights on fractures deformation from tiltmeter data measured inside the Fontaine de Vaucluse karst system. Geophysical Journal International, 208, 1389-1402. https://doi. org/10.1093/gii/ggw446

Lindstrom, G., Johansson, B., Persson, M., Gardelin, M., \& Bergstrom, S. (1997). Development and test of the distributed HBV-96 hydrological model. Journal of Hydrology, 201, 272-288. https://doi.org/10.1016/S0022-1694(97)00041-3

Longuevergne, L., Florsch, N., Boudin, F., Oudin, L., \& Camerlynck, C. (2009). Tilt and strain deformation induced by hydrologically active natural fractures: Application to the tiltmeters installed in Sainte-Croix-aux-Mines observatory (France). Geophysical Journal International, 178, 667-677. https://doi.org/10.1111/j.1365-246X.2009.04197.x

Longuevergne, L., Scanlon, B. R., \& Wilson, C. R. (2010). GRACE Hydrological estimates for small basins: Evaluating processing approaches on the High Plains Aquifer, USA. Water Resources Research, 46, W11517. https://doi.org/10.1029/2009WR008564

Lowry, A. R. (2006). Resonant slow fault slip in subduction zones forced by climatic load stress. Nature, 442, 802-805. https://doi. org/10.1038/nature05055

MacQueen, J. (1967). Some methods for classification and analysis of multivariate observations (Vol. 1, pp. 281-297). Proceedings of the fifth Berkeley symposium on mathematical statistics and probability, University of California Press, Berkeley, CA. Retrieved from https:// projecteuclid.org/euclid.bsmsp/1200512992

Milanovic, P. T. (2005). Water resources engineering in karst. Choice Reviews Online, 42(5), 42-2822. https://doi.org/10.5860/choice.42-2822 Oestreicher, N. (2018). Geodetic, hydrologic and seismological signals associated with precipitation and infiltration in the central Southern Alps (Ph.D. Thesis). New Zealand. Retrieved from https://hdl.handle.net/10063/7024

Ogata, Y. (1998). Space-time point-process models for earthquake occurrences. Annals of the Institute of Statistical Mathematics, 50, 379402. https://doi.org/10.1023/A:1003403601725

Priolo, E., Romanelli, M., Plasencia Linares, M. P., Garbin, M., Peruzza, L., Romano, M. A., et al. (2015). Seismic monitoring of an underground natural gas storage facility: The Collalto seismic network. Seismological Research Letters, 86, 109-123. https://doi. org/10.1785/0220140087

Pushpalatha, R., Perrin, C., Le Moine, N., Mathevet, T., \& Andréassian, V. (2011). A downward structural sensitivity analysis of hydrological models to improve low-flow simulation. Journal of Hydrology, 411, 66-76. https://doi.org/10.1016/j.jhydrol.2011.09.034

Rodell, M. (2016). GLDAS Noah Land Surface Model L4 monthly 0.25 x 0.25 degree version 2.1: NASA Goddard Earth Sciences Data and Information Services Center. https://doi.org/10.5067/sxavczfaqlno

Romano, M. A., Peruzza, L., Garbin, M., Priolo, E., \& Picotti, V. (2019). Microseismic portrait of the Montello thrust (southeastern Alps, Italy) from a dense high quality seismic network. Seismological Research Letters, 90, 1502-1517. https://doi.org/10.1785/0220180387

Rousseeuw, P. J. (1987). Silhouettes: A graphical aid to the interpretation and validation of cluster analysis. Journal of Computational and Applied Mathematics, 20, 53-65. https://doi.org/10.1016/0377-0427(87)90125-7

Rovida, A., Locati, M., Camassi, R., Lolli, B., \& Gasperini, P. (2020). The Italian earthquake catalogue CPTI15. Bulletin of Earthquake Engineering, 18(7), 2953-2984. https://doi.org/10.1007/s10518-020-00818-y

Schuite, J., Longuevergne, L., Bour, O., Burbey, T. J., Boudin, F., Lavenant, N., \& Davy, P. (2017). Understanding the hydromechanical behavior of a fault zone from transient surface tilt and fluid pressure observations at hourly time scales. Water Resources Research, 53(12), 10558-10582. https://doi.org/10.1002/2017WR020588

Serpelloni, E., Pintori, F., Gualandi, A., Scoccimarro, E., Cavaliere, A., Anderlini, L., et al. (2018). Hydrologically induced karst deformation: Insights from GPS measurements in the Adria-Eurasia plate boundary zone. Journal of Geophysical Research: Solid Earth, 123, 4413-4430. https://doi.org/10.1002/2017JB015252

Serpelloni, E., Vannucci, G., Anderlini, L., \& Bennett, R. A. (2016). Kinematics, seismotectonics and seismic potential of the eastern sector of the European Alps from GPS and seismic deformation data. Tectonophysics, 688, 157-181. https://doi.org/10.1016/j.tecto.2016.09.026

Silverii, F., D'Agostino, N., Métois, M., Fiorillo, F., \& Ventafridda, G. (2016). Transient deformation of karst aquifers due to seasonal and multiyear groundwater variations observed by GPS in southern Apennines (Italy). Journal of Geophysical Research: Solid Earth, 121, 8315-8337. https://doi.org/10.1002/2016JB013361

Silverii, F., Montgomery-Brown, E. K., Borsa, A. A., \& Barbour, A. J. (2020). Hydrologically induced deformation in Long Valley Caldera and adjacent Sierra Nevada. Journal of Geophysical Research: Solid Earth, 125, e2020JB019495https://doi.org/10.1029/2020JB019495

Torabi, A., Ellingsen, T. S. S., Johannessen, M. U., Alaei, B., Rotevatn, A., \& Chiarella, D. (2019). Fault zone architecture and its scaling laws: Where does the damage zone start and stop?. Geological Society of London Special Publications, 496, 99-124. https://doi. org/10.1144/SP496-2018-151 
van Dam, T., Wahr, J., Milly, P. C. D., Shmakin, A. B., Blewitt, G., Lavallée, D., \& Larson, K. M. (2001). Crustal displacements due to continental water loading. Geophysical Research Letters, 28, 651-654. https://doi.org/10.1029/2000GL012120

Watkins, M. M., Wiese, D. N., Yuan, D.-N., Boening, C., \& Landerer, F. W. (2015). Improved methods for observing Earth's time variable mass distribution with GRACE. Journal of Geophysical Research: Solid Earth, 120, 2648-2671. https://doi.org/10.1002/2014JB011547

Zhuang, J., Ogata, Y., \& Vere-Jones, D. (2002). Stochastic declustering of space-time earthquake occurrences. Journal of the American Statistical Association, 97(458), 369-380. https://doi.org/10.1198/016214502760046925

\section{References From the Supporting Information}

Al-Zoubi, M. B., \& Rawi, M. (2008). An efficient approach for computing silhouette coefficients. Journal of Computer Science, 4, $252-255$. https://doi.org/10.3844/jcssp.2008.252.255

Altamimi, Z., Collilieux, X., \& Métivier, L. (2011). ITRF2008: An improved solution of the international terrestrial reference frame. Journal of Geodesy, 85, 457-473. https://doi.org/10.1007/s00190-011-0444-4

Bevis, M., \& Brown, A. (2014). Trajectory models and reference frames for crustal motion geodesy. Journal of Geodesy, 88, 283-311. https:// doi.org/10.1007/s00190-013-0685-5

Boehm, J., Heinkelmann, R., \& Schuh, H. (2007). Short note: A global model of pressure and temperature for geodetic applications. Journal of Geodesy, 81, 679-683. https://doi.org/10.1007/s00190-007-0135-3

Dong, D., Fang, P., Bock, Y., Cheng, M., \& Miyazaki, S. (2002). Anatomy of apparent seasonal variations from GPS-derived site position time series. Journal of Geophysical Research, 107(B4), ETG 9-1-ETG 9-16. https://doi.org/10.1029/2001JB000573

Dong, D., Fang, P., Bock, Y., Webb, F., Prawirodirdjo, L., Kedar, S., \& Jamason, P. (2006). Spatiotemporal filtering using principal component analysis and Karhunen-Loeve expansion approaches for regional GPS network analysis. Journal of Geophysical Research, 111, B03405. (B4), 2075https://doi.org/10.1029/2005JB003806

Dong, D., Herring, T., \& King, R. (1998). Estimating regional deformation from a combination of space and terrestrial geodetic data. Journal of Geodesy, 72(4), 200-214. https://doi.org/10.1007/s001900050161

Garcia-Aristizabal, A., Bucchignani, E., \& Manzi, M. P. (2017). Patterns in climate-related parameters as proxy for rainfall deficiency and aridity: Application to Burkina Faso. ASCE-ASME Journal of Risk and Uncertainty in Engineering Systems, Part A: Civil Engineering, 3, A4016001. https://doi.org/10.1061/AJRUA6.0000860

Garcia-Aristizabal, A., Bucchignani, E., Palazzi, E., D'Onofrio, D., Gasparini, P., \& Marzocchi, W. (2015). Analysis of non-stationary climate-related extreme events considering climate change scenarios: An application for multi-hazard assessment in the Dar es Salaam region, Tanzania. Natural Hazards, 75, 289-320. https://doi.org/10.1007/s11069-014-1324-z

Garcia-Aristizabal, A., Caciagli, M., \& Selva, J. (2016). Considering uncertainties in the determination of earthquake source parameters from seismic spectra. Geophysical Journal International, 207, 691-701. https://doi.org/10.1093/gji/ggw303

Han, J., Kamber, M., \& Pei, J. (2011). Data mining concepts and techniques (3rd ed.): Morgan Kaufmann.

Harris, R. A., \& Simpson, R. W. (1992). Changes in static stress on southern California faults after the 1992 Landers earthquake. Nature, 360, 251-254. https://doi.org/10.1038/360251a0

IS-EPOS. (2016). Completeness magnitude estimation [Web application/Source code]. Retrieved from https://tcs.ah-epos.eu/

Kass, R. E., \& Raftery, A. E. (1995). Bayes factors. Journal of the American Statistical Association, 90, 773-795. https://doi.org/10.1080/01 621459.1995 .10476572

Kaufman, L., \& Rousseeuw, P. J. (Eds.), (1990). Partitioning around medoids (program PAM). In L. Kaufman, \& P. J. Rousseeuw (Eds.), Finding groups in data (Wiley Series in Probability and Statistics, pp. 68-125). Hoboken, NJ: John Wiley \& Sons, Inc. https://doi. org/10.1002/9780470316801.ch2

Lagler, K., Schindelegger, M., Böhm, J., Krásná, H., \& Nilsson, T. (2013). GPT2: Empirical slant delay model for radio space geodetic techniques. Geophysical Research Letters, 40, 1069-1073. https://doi.org/10.1002/grl.50288

Leptokaropoulos, K. M., Karakostas, V. G., Papadimitriou, E. E., Adamaki, A. K., Tan, O., \& Inan, S. (2013). A homogeneous earthquake catalog for western turkey and magnitude of completeness determination. Bulletin of the Seismological Society of America, 103, 27392751. https://doi.org/10.1785/0120120174

Lewis, S. M., \& Raftery, A. E. (1997). Estimating Bayes factors via posterior simulation with the Laplace-Metropolis estimator. Journal of the American Statistical Association, 92, 648-655. https://doi.org/10.1080/01621459.1997.10474016

Lyard, F., Lefevre, F., Letellier, T., \& Francis, O. (2006). Modelling the global ocean tides: Modern insights from FES2004. Ocean Dynamics, 56, 394-415. https://doi.org/10.1007/s10236-006-0086-x

Mignan, A., \& Woessner, J. (2012). Estimating the magnitude of completeness for earthquake catalogs: Community Online Resource for Statistical Seismicity Analysis. https://doi.org/10.5078/corssa-00180805

Nash, J. E., \& Sutcliffe, J. V. (1970). River flow forecasting through conceptual models part I-A discussion of principles. Journal of Hydrology, 10, 282-290. https://doi.org/10.1016/0022-1694(70)90255-6

Ogata, Y. (1988). Statistical models for earthquake occurrences and residual analysis for point processes. Journal of the American Statistical Association, 83, 9-27. https://doi.org/10.1080/01621459.1988.10478560

Ogata, Y., Matsu'ura, R. S., \& Katsura, K. (1993). Fast likelihood computation of epidemic type aftershock-sequence model. Geophysical Research Letters, 20, 2143-2146. https://doi.org/10.1029/93GL02142

Oudin, L., Hervieu, F., Michel, C., Perrin, C., Andréassian, V., Anctil, F., \& Loumagne, C. (2005). Which potential evapotranspiration input for a lumped rainfall-runoff model? Journal of Hydrology, 303, 290-306. https://doi.org/10.1016/j.jhydrol.2004.08.026

Petrie, E. J., King, M. A., Moore, P., \& Lavallée, D. A. (2010). Higher-order ionospheric effects on the GPS reference frame and velocities Journal of Geophysical Research, 115, B03417. https://doi.org/10.1029/2009JB006677

Raftery, A. E. (1995). Hypothesis testing and model. In W. R. Gilks, S. Richardson and D. J. Spiegelhalter (Eds.), Markov chain Monte Carlo in practice (pp. 165-187). London: Chapman \& Hall

Schmid, R., Rothacher, M., Thaller, D., \& Steigenberger, P. (2005). Absolute phase center corrections of satellite and receiver antennas. GPS Solutions, 9, 283-293. https://doi.org/10.1007/s10291-005-0134-x

Schmid, R., Steigenberger, P., Gendt, G., Ge, M., \& Rothacher, M. (2007). Generation of a consistent absolute phase-center correction model for GPS receiver and satellite antennas. Journal of Geodesy, 81, 781-798. https://doi.org/10.1007/s00190-007-0148-y

Serpelloni, E., Casula, G., Galvani, A., Anzidei, M., \& Baldi, P. (2006). Data analysis of Permanent GPS networks in Italy and surrounding region: application of a distributed processing approach. Annales de Geophysique, 49, 897-928. https://doi.org/10.4401/ag-4410 
Serpelloni, E., Faccenna, C., Spada, G., Dong, D., \& Williams, S. D. P. (2013). Vertical GPS ground motion rates in the Euro-Mediterranean region: New evidence of velocity gradients at different spatial scales along the Nubia-Eurasia plate boundary. Journal of Geophysical Research: Solid Earth, 118, 6003-6024. https://doi.org/10.1002/2013JB010102

Utsu, T., Ogata, Y., \& Matsu'ura, S. R. (1995). The centenary of the Omori formula for a decay law of aftershock activity. Journal of Physics of the Earth, 43, 1-33. https://doi.org/10.4294/jpe1952.43.1

van Stiphout, T., Marsan, D., \& Zhuang, J. (2012). Seismicity declustering: Community Online Resource for Statistical Seismicity Analysis. https://doi.org/10.5078/corssa-52382934

Wiemer, S. (2000). Minimum magnitude of completeness in earthquake catalogs: Examples from Alaska, the Western United States, and Japan. Bulletin of the Seismological Society of America, 90, 859-869. https://doi.org/10.1785/0119990114 